\title{
Adaptation of the human visual system to the statistics of letters and line configurations
}

\author{
Claire H.C. Chang ${ }^{\mathrm{a}, *}$, Christophe Pallier ${ }^{\text {b,c,d,e }}$, Denise H. Wu ${ }^{\mathrm{f}}$, Kimihiro Nakamura ${ }^{\text {b,c,e,g }}$, Antoinette Jobert ${ }^{\text {b,c,e }}$,
} W.-J. Kuo a , Stanislas Dehaene ${ }^{\text {b,c,e,g }}$

a Institute of neuroscience, National Yang-Ming University, Taipei, Taiwan

b Cognitive Neuroimaging Unit, INSERM, Gif-sur-Yvette, France

c CEA, DSV, I2BM, NeuroSpin Center, Paris, France

d Centre National de la Recherche Scientifique, Paris, France

e University Paris-Sud, Paris, France

${ }^{\mathrm{f}}$ National Central University, Jhongli, Taiwan

g Collège de France, Paris, France

\section{A R T I C L E I N F O}

\section{Article history:}

Received 5 May 2015

Accepted 8 July 2015

Available online 17 July 2015

\section{Keywords:}

Environmental statistics

Adaptation

Visual recognition

Reading

Literacy

fMRI

\begin{abstract}
A B S T R A C T
By adulthood, literate humans have been exposed to millions of visual scenes and pages of text. Does the human visual system become attuned to the statistics of its inputs? Using functional magnetic resonance imaging, we examined whether the brain responses to line configurations are proportional to their natural-scene frequency. To further distinguish prior cortical competence from adaptation induced by learning to read, we manipulated whether the selected configurations formed letters and whether they were presented on the horizontal meridian, the familiar location where words usually appear, or on the vertical meridian. While no natural-scene frequency effect was observed, we observed letter-status and letter frequency effects on bilateral occipital activation, mainly for horizontal stimuli. The findings suggest a reorganization of the visual pathway resulting from reading acquisition under genetic and connectional constraints. Even early retinotopic areas showed a stronger response to letters than to rotated versions of the same shapes, suggesting an early visual tuning to large visual features such as letters.
\end{abstract}

(c) 2015 Elsevier Inc. All rights reserved.

\section{Introduction}

Many neuroscientists and theorists have proposed the idea that the visual system has internalized the statistical properties of the environment (Berkes et al., 2011; Geisler, 2008; Girshick et al., 2011; Long and Purves, 2003; Shepard, 2002; Simoncelli and Olshausen, 2001). For example, environmental statistics have been proposed to be the basis of the Gestalt rules of proximity (Brunswik, 1956) and the principle of good continuation (Gilbert et al., 2001b). The adaptation of the visual system to environmental regularities could occur both at the evolutionary scale (Shepard, 2002) and during ontogenetic development (Berkes et al., 2011; Blakemore and Cooper, 1970; Held and Hein, 1963). In the Bayesian perspective, environmental statistics get internalized and later enter as a prior which is used to help disambiguate future inputs (Kersten et al., 2004; Knill and Pouget, 2004). Classical visual illusions such as the horizontal-vertical illusion (greater apparent size of a vertical bar compared to a horizontal bar) may be explained by scene statistics (Howe and Purves, 2002). This and other illusions may be

\footnotetext{
* Corresponding author at: Room 812, 8F, Library, Information, and Research Building, National Yang-Ming University, No. 155, Sec. 2, Linong Street, Taipei, 112 Taiwan ROC.

E-mail address: hcchang73@gmail.com (C.H.C. Chang).
}

accounted for by supposing that early visual neuronal circuits are modified by experience, such that greater populations of cells are assigned to more frequent features of the environment (Girshick et al., 2011) and that their horizontal connections internalize the statistics of feature co-occurrence (Hess et al., 2003).

In the present study, we examined whether the frequency distribution of line configurations in the environment is reflected in the human visual system. Changizi et al. (2006) discovered an interesting statistical regularity in the frequency with which the topological configurations formed by image contours, such as T, L, or X configurations, occur in the visual environment. They counted the frequency of each topological configuration of two or three contour lines in pictures of the natural or artificial human environment, and observed a systematic ordering (Fig. 1a). For instance, amongst the two-line configurations, the "L" configuration was always more frequent than "T", which in turn was more frequent than " $\mathrm{X}$ ". Crucially, this is not the case in simple random arrangements of lines. Furthermore, human visual signs, as taken from alphabets, logographic writing systems and other symbol systems, followed the same statistical distribution, such that the frequency ranks of the configurations in these two domains were positively correlated (Fig. 1a). In other words, the frequency distribution of line configurations in human cultural signs mimicked that found in natural scenes. 
A

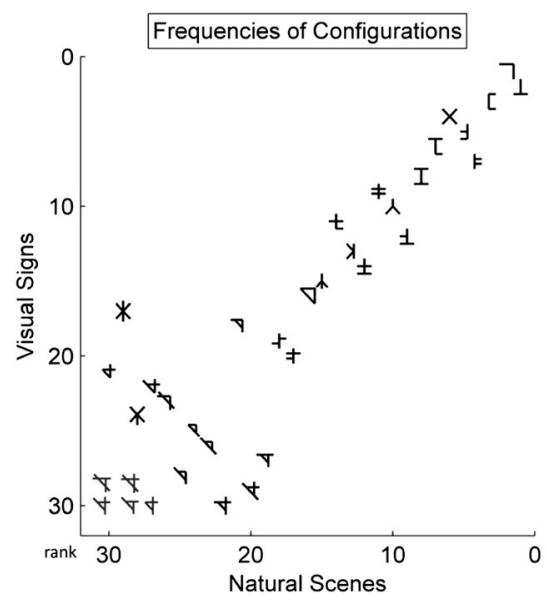

B Probe

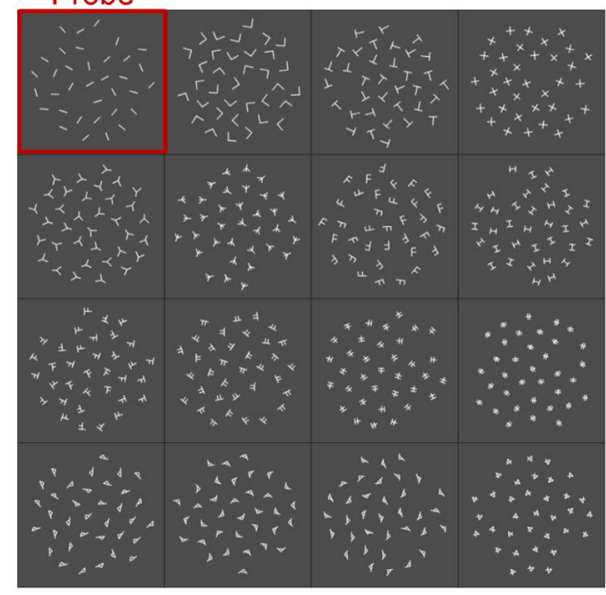

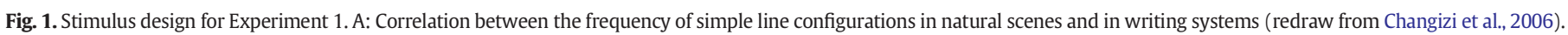

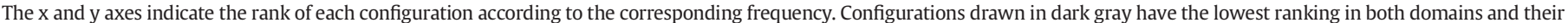

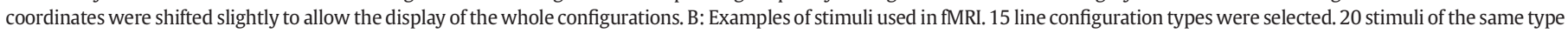

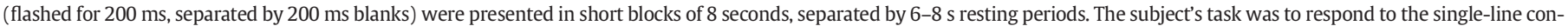
figuration (top left) which appeared occasionally inside the blocks.

Such a strong link between environmental statistics and cultural inventions is in agreement with the "neuronal recycling hypothesis" whereby novel cultural acquisition such as writing maps onto pre-existing cortical systems, thus constraining the range of cross-cultural variations (Dehaene and Cohen, 2011). According to this hypothesis, Changizi et al.'s (2006) finding implies that configurations that are frequently observed in the natural environment are more likely to be selected as visual signs, because they are better encoded in the visual system (Dehaene, 2009).

The above argument is based solely on statistical evidence, and lacks direct evidence that line configuration statistics are encoded in the visual system. Neurophysiological evidence does suggest that neurons in the primate infero-temporal cortex can be sensitive to specific line configurations that form non-accidental topological properties (Brincat and Connor, 2004, 2006; Tanaka, 2003). However, these studies have not yet investigated whether the cortical representation of these features mimics their distribution in natural scenes. Here, we used fMRI in humans to investigate this issue. Our hypothesis was that visual activation in response to line configurations should be directly proportional to their natural-scene frequency.

Where in the visual pathway might this effect occur? A prediction for the locus of the natural-scene frequency effect could be made based on hierarchical models of visual recognition (Dehaene et al., 2005; DiCarlo et al., 2012; Rolls and Stringer, 2006; Serre et al., 2007; Ullman, 2007). All of these models assume that the ventral occipitotemporal pathway comprises a hierarchy of neural detectors with progressively larger receptive fields, each tuned to increasingly complex and abstract combinations of visual features. In humans, the Local Combination Detectors model (Dehaene et al., 2005) assumes that written word recognition rests on a reorientation of this architecture towards the detection of letters and their combinations. Based on several prior fMRI experiments (Dehaene et al., 2004; Vinckier et al., 2007), the model proposes specific cortical areas for each step: line configurations and letter fragments in area V2 and V4, abstract letter identities and their combinations in the more anterior visual word form area (VWFA) (Cohen et al., 2002). Under the neuronal recycling hypothesis, even prior to reading acquisition, these areas may already exhibit a bias for recognizing line configurations, which would make it particularly suitable for recognition of written words (Dehaene et al., 2005; Dehaene, 2009; Szwed et al., 2011).

In addition to V2, V4 and VWFA, one should also consider the possibility that the primary visual cortex itself may exhibit sensitivity, not only to elementary contours, but also to their frequent combinations. Recent electrophysiological (McManus et al., 2011) and imaging (Sigman et al., 2005) studies have revealed that training in shape detection changes cortical responses even in the calcarine cortex, indicating that experience could induce a sensitivity to complex visual features in early retinotopic areas V1 and/or V2. fMRI studies of reading indicate that even area V1 is more activated by letter strings than by scrambled stimuli with matched visual features (Szwed et al., 2011, 2014). Indeed, the calcarine cortex, at the location of area V1, shows a stronger response to horizontal checkerboards in literate, who used to read horizontally, than in illiterate subjects (Dehaene et al., 2010). Those findings suggest that reading acquisition may lead to perceptual learning for frequent letter shapes in area as early as V1. In this case, an effect of the natural-scene frequencies of line configurations might also be observed in early retinotopic cortex.

In summary, we aim to test whether the frequency distribution of simple line configurations in natural scenes is reflected in the visual cortex. In Experiment 1, we study the fMRI responses to the line configurations studied by Changizi et al. (2006). Given that the most frequent configurations in natural scenes are also those most frequently used in human writing systems, the existence of such effect may support the view that human writing systems have evolved from prior cortical competence. Furthermore, in literate adults, the adaptation to environmental statistics includes a novel cultural environment: written texts. Thus, one might expect the processing of simple line configurations to also be under the influence of reading experience, a prediction which is further investigated in Experiment 2.

\section{Experiment 1}

In Experiment 1, we collected fMRI data in 18 subjects while they simply viewed arrays comprising 15 different types of line configurations, selected to span a broad range of natural-scene frequencies, as computed by Changizi et al. (2006)(Fig. 1). We used a correlation approach to probe the whole brain for activations correlated with the logarithm of natural scene frequencies.

\section{Methods}

\section{Participants}

Eighteen right-handed ( 9 female), 18-30 year-old native French speakers, participated in the present fMRI experiment. They had no 
history of neurological or psychiatric disease, and had normal or corrected-to-normal vision. Written informed consents were given. The project was approved by the local ethics committee.

\section{Stimuli}

Fifteen configurations were selected from the paper by Changizi et al. (2006), which provides the frequencies of line configurations in pictures of the human environment (landscapes, cities, etc.). In this study, we use as a short-hand the expression 'natural-scene frequency' to refer to the logarithm of the average frequencies of line configurations in such pictures.

For each type of line configuration, we used a matlab program to generate 10 images, each comprising 35 randomly oriented items of the same type (Fig. 1b). The item width was 0.83-1.22 degrees of visual angle. The images were 18.9 by 18.9 degrees of visual angle. Total contour length and number of "on" pixels were matched (the standard deviation of the numbers of "on" pixels was less than $0.1 \%$ across all conditions).

\section{Design and procedure}

Each participant took part in six fMRI runs. The total scanning time was around 42 minutes. Each run lasted about 7 minutes and contained 30 mini-blocks of $8 \mathrm{~s}$ separated by rest periods of $4-8 \mathrm{~s}$. Each mini-block comprised 20 images of the same type of line configuration, each of which was presented for $200 \mathrm{~ms}$ after a fixation interval of $200 \mathrm{~ms}$. Each run comprised two mini-blocks of each of the 15 distinct types of line configuration. The 30 blocks were ordered randomly. To maintain the participants' attention on the visual stimuli with a minimally demanding task, participants were required to monitor the stimulus stream for the presence of a target probe consisting of a picture with single-line bars, also displayed for $200 \mathrm{~ms}$. The target appeared in half of the mini-blocks, and participants were instructed to press a button as fast as possible upon seeing it. Blocks with a target were randomly chosen. The target always occurred in the middle of blocks (replacing one of the images 6-12 within the block of 20 images). In an effort to maintain attention throughout each 8-second block, subjects were not told that blocks could only contain at most one target.

\section{MRI acquisition}

The acquisition was performed with a 3-Tesla Siemens Tim Trio system. One anatomical image (voxel $=1 \times 1 \times 1.1 \mathrm{~mm}$ ) and a total of 1092 functional images were acquired using an Echo-Planar sequence sensitized to the BOLD effect ( $\mathrm{TR}=2.4 \mathrm{secs}, \mathrm{TE}=30 \mathrm{msecs}$, Matrix $=$ $64 \times 64$; Voxel size $=3 \times 3 \times 3 \mathrm{~mm} ; 40$ slices in ascending order).

\section{Data analysis}

Data processing was performed with SPM8 (Wellcome Department of Cognitive Neurology, software available at http://www.fil.ion.ucl.ac. $\mathrm{uk} / \mathrm{spm})$. The anatomical scan was spatially normalized to the avg152 T1-weighted brain template defined by the Montreal Neurological Institute using the default parameters (nonlinear transformation). Functional volumes were realigned to correct for movements, spatially normalized using the parameters obtained from the normalization of the anatomy, and smoothed with an isotropic Gaussian kernel $(\mathrm{FWHM}=5 \mathrm{~mm})$.

In a first SPM model, experimental effects at each voxel were estimated using a multi-run design matrix modeling the 15 configurations, the probe trials, and the 6 movement parameters computed at the realignment stage. Each block was modeled as an epoch lasting 8 seconds, and each probe trial as a punctual event. The regressors were created by convolving these epochs by the standard SPM hemodynamic response function. Contrasts averaging the regression weights associated with each configuration were computed.

These estimates of individual effect sizes were entered in a secondlevel analysis with one regressor for each configuration and each participant (one-way within-subject ANOVA model). To search for regions showing an effect of natural-scene frequency, we used a contrast with weights proportional to log natural-scene frequency, testing for increasing activation across the configurations in the ANOVA model. We also tested second-level regression models pitting two variables against each other, as described further below. Unless otherwise stated, statistics were thresholded at voxel wise $\mathrm{p}<0.001$ (uncorrected), with an additional correction for multiple comparisons across the whole-brain volume based on cluster extent ( $\mathrm{p}<0.05$, FDR corrected). Regions showing significant effects were labeled with an automated anatomical labeling system (AAL; Tzourio-Mazoyer et al., 2002).

\section{Results}

\section{Behavioral results}

Reaction times (RT) outside the range of individual mean $\pm 3 \mathrm{sd}$ were excluded. Across participants, the mean RT was $445 \mathrm{~ms}$ ( $\mathrm{SE}=$ $13 \mathrm{~ms}$, range $=348-633 \mathrm{~ms}$ ), and the mean accuracy was $97 \%$ ( $\mathrm{SE}=1 \%$, range $=82-100 \%$ ). The RTs and accuracies of each configuration were listed in Appendix Table 1. Repeated one-way ANOVAs revealed small but significant differences between configurations in RT $(\mathrm{F}(14,238)=2.73 ; \mathrm{p}<.01)$ and accuracies $(\mathrm{F}(14,238)=2.15$; $\mathrm{p}<.05)$. However, natural-scene frequency was not significantly correlated with either RT $(\mathrm{r}=0.32, \mathrm{p}=.24)$ or accuracy $(\mathrm{r}=-0.24, \mathrm{p}=$ .39). The behavioral results confirmed that the participants maintained their attention on the visual presentation.

\section{Imaging results}

Whole-brain analysis revealed a bilateral occipital cluster with a significant positive correlation indicating increasingly stronger activation for configurations with increasingly higher natural-scene frequency in early retinotopic areas (Fig. 2 and Table 1).

The scatter plots in Fig. 2 illustrate how occipital activation varies across the 15 line configurations. Although there is a clear trend as a function of natural-scene frequency, some dispersion in activation is apparent. Furthermore, one may observe that configurations corresponding to letters (shown in red), which are all of high natural-scene frequency, yield stronger activations than other configurations with nearly-equivalent frequency. To formally assess the effect of letter status, we created a multiple regression model with one regressor per participant and two regressors of interest: natural-scene frequency and letter versus non-letter status (X, T, L, H, Y and F configurations were counted as letters, although note that they often appeared as rotated in the display; this factor will be controlled in Experiment 2). In this model, the effect of natural-scene frequency ceased to reach significance anywhere in the brain, and instead there was a significant effect of letter status in bilateral occipital cortex, including bilateral V1, V2, and left V3 (Fig. 3 and Table 2). We also tested the natural-scene frequency effect within only the non-letters, again without any significant results. Thus, the results suggest that letter status, rather than frequency, drives occipital fMRI activation in educated human adults.

In an effort to confirm this conclusion while controlling for other visual variables that may be confounded with letter/non-letter status and/ or natural-scene frequency, we measured several parameters of the displays: convex area (the surface of the smallest convex polygon that contains a single line configuration item), number of line junctions, number of strokes ( 2 or 3 ), number of angles, and number of terminals (ending points of a line). The values of the variables for each configuration type are provided in Appendix Table 1. We also added as a potential confound the average response time for target detection in the corresponding block. We created several regression models in which each of these variables was pitted against natural-scene frequency, and observed that in the models including letter status or convex area, the variable 'natural-scene frequency' no longer yielded a significant effect. In a model with letter status and convex area, we only found higher occipital activation for letters than non-letters (Fig. 3). We further tested this letter status effect in models systematically including letter status and one 


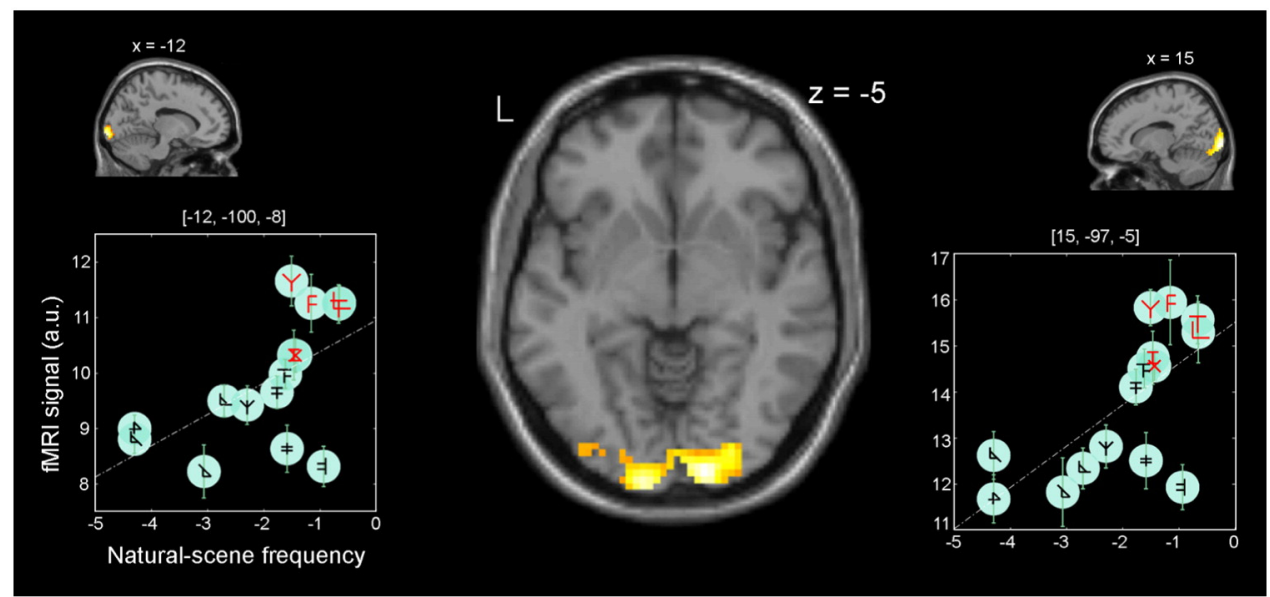

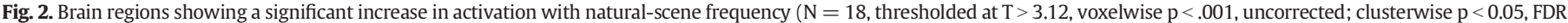

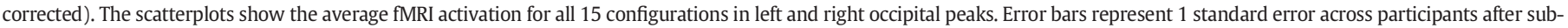
traction of each participant's individual mean. Letter-like configurations are displayed in red.

of the other variables as regressors of interest. Letter status always survived as the dominant determinant of occipital activation (Fig. 4).

We also tested for a reversed letter-status effect, namely, larger activations for non-letters than letters, as well as the negative correlation between brain activations and natural-scene frequency. No such effects were found in either the ANOVA model or the regression model including letter status and natural-scene frequency.

\section{Discussion}

In Experiment 1, we tested the hypothesis that the natural-scene frequencies of line configurations are reflected in the human visual system. As predicted, a positive correlation between natural-scene frequency and brain activation was found only in bilateral occipital visual areas, at an anatomical location corresponding to area V1/V2 and a small part of left V3. However, we also found that this effect could be driven by a partially confounded variable, namely, whether or not a given line configuration forms a letter of the Roman alphabet. As observed by Changizi et al. (2006), in all cultures, the shapes that are used as letters tend to be of high natural-scene frequency. Nevertheless, our stimulus set included some non-letter line configurations with a natural-scene frequency nearly as high as that of the letters. Multiple regression analyses suggested that letter status, not natural-scene frequency, was responsible for the changes in occipital activation.

Such an effect of letter status is compatible with prior observations that early visual cortex is modified by literacy acquisition (Dehaene et al., 2010) and becomes sensitive to letters strings more than to other stimuli of matched complexity (Szwed et al., 2011, 2014). Note that this effect is not incompatible with the general hypothesis that the visual system internalizes the statistics of environmental inputs. It should be acknowledged that, for highly literate subjects, the environment most likely includes a high proportion of text, which may therefore bias the statistics away from those of natural scenes and towards those of the subject's writing system.

Experiment 1, however, was not specifically designed to test for a letter effect, but solely to investigate the effect of natural-scene frequency, and the letter effect was only seen in a post-hoc analysis. In Experiment

Table 1

Brain regions showing natural-scene frequency effect in Experiment 1.

\begin{tabular}{|c|c|c|c|c|c|c|c|}
\hline Cluster Size & & & & $\mathrm{T}$ & $\mathrm{X}$ & $\mathrm{Y}$ & Z \\
\hline \multirow[t]{3}{*}{659} & Occipital & Calcarine & $\mathrm{R}$ & 6.32 & 15 & -101 & 0 \\
\hline & & Cuneus & $\mathrm{R}$ & 6.06 & 18 & -97 & 7 \\
\hline & & Inf. & $\mathrm{L}$ & 5.75 & -12 & 100 & -8 \\
\hline
\end{tabular}

2, we therefore aimed to provide a replication in which the effects of natural-scene frequency and letter status were manipulated independently. To this aim, we capitalized on the fact that, in written texts, letters appear at a specific angle. Beyond about 45 degrees of rotations, the recognition of letters and words becomes severely degraded, accompanied by a sudden onset of parietal lobe activations suggesting serial

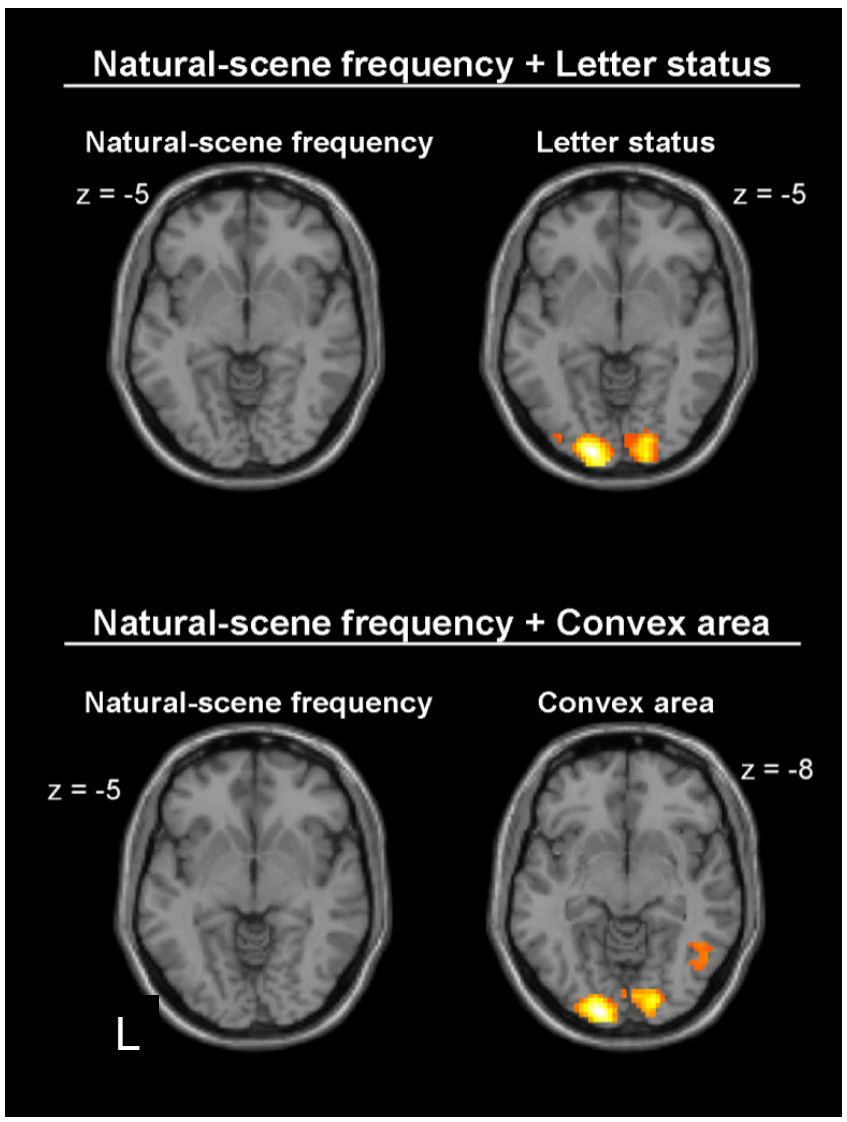

Fig. 3. Disappearance of the effect of natural-scene frequency once other variables are considered. The results of two regression models are shown, each containing two regressors of interest: the line configuration frequency in natural scenes and either the letter status (whether the configuration forms a letter of the Roman alphabet or not) or the convex area (estimating the surface occupied by an individual line configuration item in the display). Images are SPMt maps ( $\mathrm{N}=18$, thresholded at $\mathrm{T}>3.12$, voxelwise $\mathrm{p}<.001$, uncorrected; clusterwise $\mathrm{p}<0.05$, FDR corrected) 
Table 2

Brain regions showing letter status effect in Experiment 1.

\begin{tabular}{|c|c|c|c|c|c|c|c|}
\hline Cluster Size & & & & $\mathrm{T}$ & $\mathrm{X}$ & $\mathrm{Y}$ & $\mathrm{Z}$ \\
\hline \multirow[t]{3}{*}{531} & Occipital & Mid. & $\mathrm{L}$ & 9.11 & -18 & -94 & -5 \\
\hline & & Mid. & $\mathrm{L}$ & 5.04 & -27 & -85 & 10 \\
\hline & & Mid. & $\mathrm{L}$ & 4.80 & -39 & -91 & 4 \\
\hline \multirow[t]{3}{*}{513} & Occipital & Mid. & $\mathrm{R}$ & 8.45 & 24 & -91 & 7 \\
\hline & & Calcrine & $\mathrm{R}$ & 8.05 & 18 & -100 & 1 \\
\hline & & Lingual & $\mathrm{R}$ & 4.58 & 6 & -85 & -11 \\
\hline
\end{tabular}

effortful deciphering (Cohen et al., 2008). In Experiment 2, we therefore presented the very same topological line configuration at two different angles, only one of which corresponded to a letter. We selected 8 letters (AKYHXFTL) and created a fixed set of 8 corresponding non-letter stimuli by rotation or symmetry (Fig. 5). Although the range of variation in natural-scene frequency was smaller than that in Experiment 1, the 8 configurations still spanned more than two orders of magnitude in the Changizi et al. scale (Appendix Table 2), thus achieving an orthogonal design with independent factors of letter status and natural-scene frequency.

Experiment 2 also included another manipulation of the retinotopic location of the items. In Experiment 1, we attempted to maximize the effect by covering the available visual field with many items. In Experiment 2 , the stimuli were presented in a more restricted part of the visual field, either along the horizontal or the vertical meridian (Fig. 5). Because the Roman alphabetic system is based on horizontal lines read from left to right, expert readers get considerably more training in letter decoding along the horizontal meridian. Although a page of text may fill a large part of the visual field, the reader's attention is typically focused on the letters left and right of fixation, and this is likely to have a determinant effect on the acquisition of visual expertise. Indeed, behavioral and brain-imaging evidence suggests an enhanced representation of stimuli presented at or near the horizontal meridian in expert readers (Dehaene et al., 2010; Nazir et al., 2004). Accordingly, one may predict a larger effect of letter status in retinotopic cortical regions coding for the horizontal meridian, than in those coding for the vertical meridian.
Conversely, one may hope to find a purer effect of natural-scene frequency, less strongly affected by reading experience, for stimuli presented along the vertical meridian.

\section{Experiment 2}

Methods

\section{Participants}

After exclusion of one subject (see below), 18 right-handed, 18-30 year-old native French speakers ( 10 female, 8 male) were retained in this fMRI experiment. They had no history of neurological or psychiatric disease and normal or corrected to normal vision. Written informed consents were given. The project was approved by the local ethics committee.

\section{Stimuli}

Eight letters were selected: AKYHXFTL. We wrote a matlab program to display them in simple line form. For each letter, we selected a transformation (flipping and/or rotation ranging from 55 to 180 degrees) to create a corresponding non-letter. We endeavored to match letters and non-letters for the number of vertical and horizontal lines, with the single exception of configuration " $\mathrm{X}$ ". This was done to avoid a confound between letter/non-letter status and line orientation, since it is known that cells whose receptive fields fall near the vertical and horizontal meridians exhibit a preference for vertical and horizontal lines, respectively (Furmanski and Engel, 2000).

Pictures corresponding to thirty-two conditions ( 8 configurations $\mathrm{x}$ 2 letter status $x 2$ presentation orientation) were created (Fig. 5). Each picture contained 10 items of the same line configuration, either horizontally or vertically aligned, with a small spatial jitter (Fig. 5). The size of each item was proportional to the distance from fixation, in order to compensate for the increase in receptive field size and the corresponding loss in spatial resolution. The formula we used for item size (item size in degrees $=0.15 \mathrm{x}$ distance from the fixation in degrees +0.48 ) was derived from Harvey and Dumoulin (2011). The pictures were 19.7 by 19.7 degrees of visual angle.

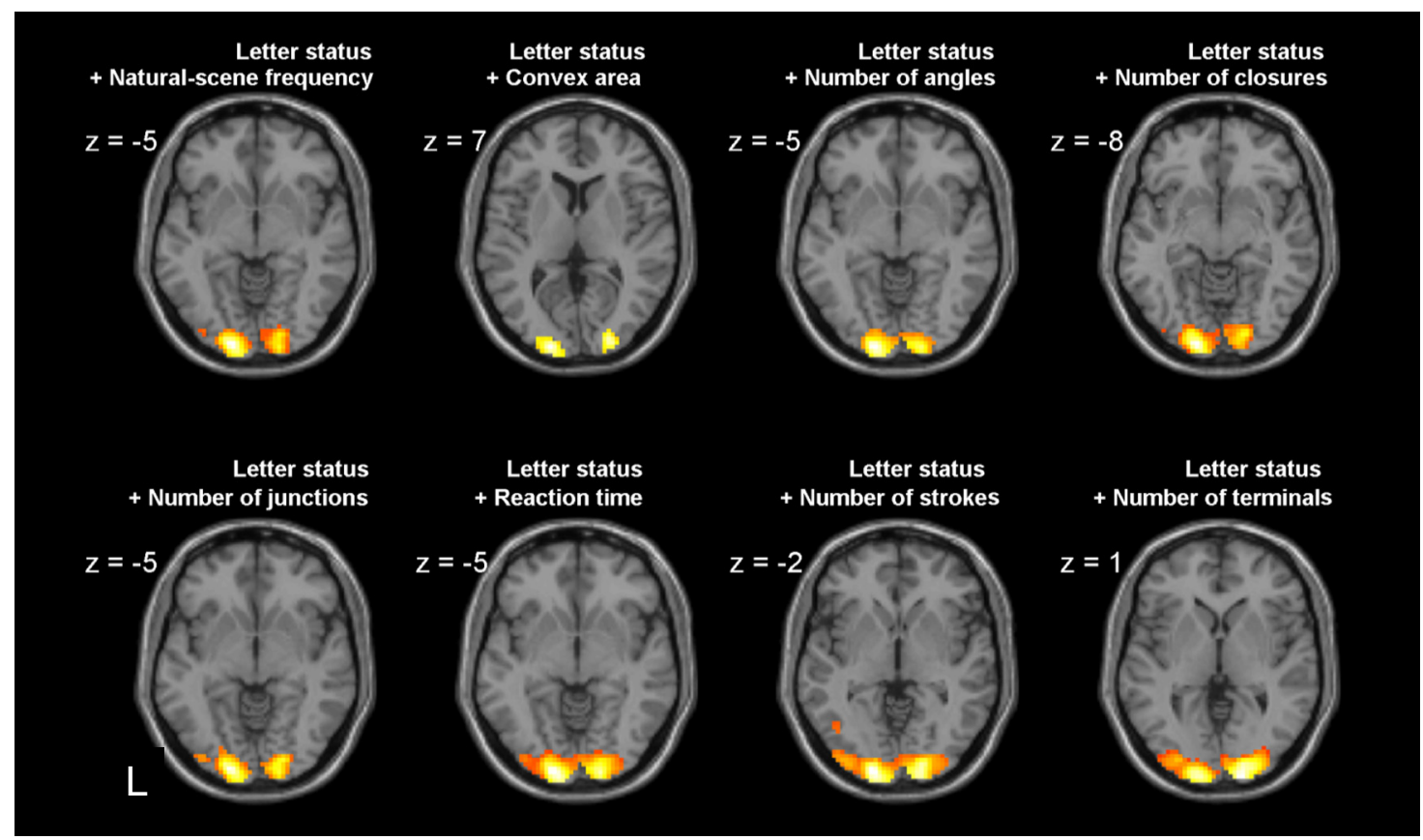

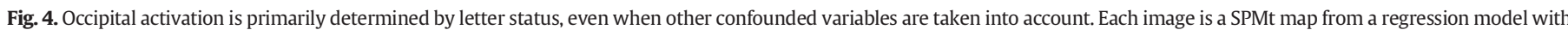
two regressors: letter status and one of the other variables $(\mathrm{N}=18$, thresholded at $\mathrm{T}>3.12$, voxelwise $\mathrm{p}<.001$, uncorrected; clusterwise $\mathrm{p}<0.05$, FDR corrected). 
A A K Y H X F T L
Non-letters

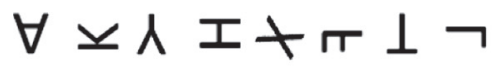

B

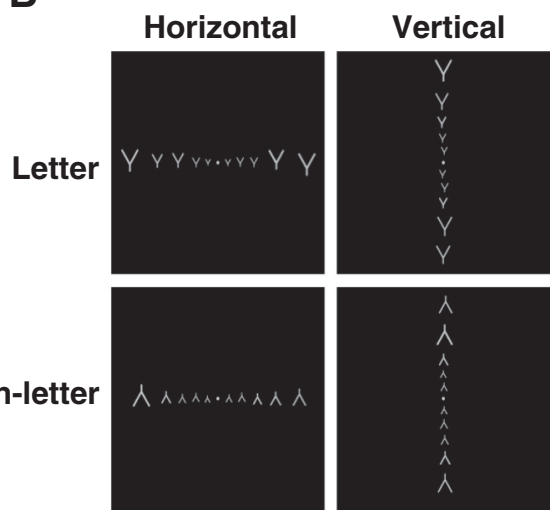

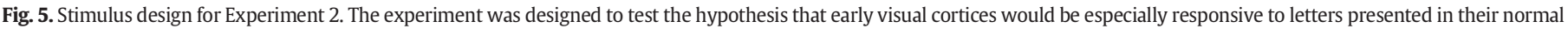

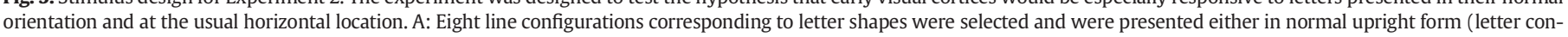

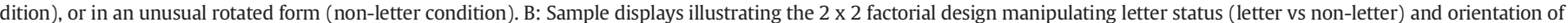
presentation (identical configurations were presented along the vertical or the horizontal meridian).

\section{Design and procedure}

The procedure was similar to Experiment 1, except the number of blocks (32) and the task. In order to better equate task difficulty across the different line configurations, the bar detection task used in Experiment 1 was replaced by a color detection task: we asked the participant to press a button whenever they detected a colored item in the pictures. The colored probe appeared 40 times in a pseudo-randomized order, so that the probe never occurred as the first or last trial in a block, and that any two probes were separated by at least three trials.

\section{MRI acquisition}

The acquisition was performed with a 3 Tesla Siemens Tim Trio system. One anatomical image (voxel $=1 \times 1 \times 1.1 \mathrm{~mm}$ ) and a total of 1890 functional images were acquired using a multiband sequence developed by the Center for Magnetic Resonance Research (CMRR) (Feinberg et al., 2010; Moeller et al., 2010; Xu et al., 2013) and sensitized to the BOLD effect $(\mathrm{TR}=1.5 \mathrm{secs}$, TE $=32$ msecs, Matrix $=128 \times 128$; Voxel size $=1.5 \times 1.5 \times 1.5 \mathrm{~mm} ; 54$ axial slices covering the occipital and most inferior part of the temporal lobe).

\section{MRI analyses}

The data was preprocessed with the same procedure as in Experiment 1 . In the first level SPM models, experimental effects at each voxel were estimated using a multi-run design matrix modeling the eight configurations, targets in the four position (right, left, upper, lower), and the six movement parameters. Each block was modeled as an epoch lasting 8 seconds, and each probe trial as event with zero duration. The regressors were created by convolving these epochs by the standard SPM hemodynamic response function. Contrasts averaging the regression weights associated with each configuration were computed.

These estimates of the individual effect sizes were entered in a second-level analysis with one regressor for each configuration, as well as each participant. The analysis was done within a mask including the occipital regions, lingual gyrus, and fusiform gyrus from the Wake Forest University (WFU) PickAtlas (Maldjian et al., 2003). Specific regions of interest (ROIs) described in the next paragraph were also included. For the voxel-based analysis, the activations were thresholded at $p<.005$ and corrected at cluster level FDR $p<0.05$.

\section{ROI analyses}

To perform the analysis of regions of interest (ROIs), masks of left and right V1/V2, V3/V4, and V5 based on a cytoarchitectonic maximum probability map (Eickhoff, et al., 2005) were generated using SPM
Anatomy Toolbox version 1.8 (http://www.fz-juelich.de/inm/inm-1/ spm_anatomy_toolbox). Masks of left and right FG1 and FG2 as described in Caspers et al. (2013) were used. The mask of VWFA was a $10 \mathrm{~mm}$ sphere around the classical coordinates (MNI $[-42,-57$, -12 ]) (Cohen et al., 2002). We flipped the mask of VWFA to get its counter-part in right hemisphere (rVWFA). The masks of lateral occipital areas (LO) were based on the centroids of LO1 and LO2 provided by Larson and Heeger (Larsson and Heeger, 2006) and generated with Marsbar (Brett et al., 2002).

For the early retinotopic areas (V1/V2 and V3/V4), we localized regions corresponding to the horizontal and vertical meridians by asking the participants to go through a localizer run after the main experiment. The localizer run included 25 blocks of flashing horizontal checkerboard and 25 blocks of flashing vertical checkerboard. Within each hemisphere, ROIs more sensitive to stimuli along the horizontal meridian ( $\mathrm{H}$ meridian) in V1/V2 and V3/V4 were determined by selecting the 30 voxels most responsive to horizontal than to vertical checkerboards. These subject-specific ROIs were then used to extract response to horizontally presented stimuli. Conversely, ROIs more sensitive to stimuli along the vertical meridian (V meridian) were determined by selecting the 30 most active voxels showing the opposite pattern. These subject-specific ROIs were then used to extract responses to the vertically presented stimuli. For higher visual regions, fixed subject-independent masks were used, because in those regions the meridian localizer no longer provided systematic distinctions of horizontal and vertical meridians within each subject, consistent with previous publications on retinotopy (Engel et al., 1997; Wotawa et al., 2005).

To test the effect of letter status in the ROI analysis, a paired T-test was applied to each ROI under the horizontal and vertical presentation conditions. To test the frequency effect and the interaction between letter status and the other factors, we used a mixed model with participants as random effects and letter status, orientation of presentation, natural-scene frequency, and letter frequency as fixed effects.

Results

\section{Behavioral result}

Across participants, the mean accuracy of the colored item detection task was $98 \%$ ( $\mathrm{SE}=0.7 \%$, range $=88-100 \%$ ) and the mean RT was $468 \mathrm{~ms}$ ( $\mathrm{SE}=9.17 \mathrm{~ms}$, range $=367-535 \mathrm{~ms}$ ). The participant with the lowest accuracy ( $85 \%$ ) also yielded the longest RT (624 ms). Considering the difference in performance between this participant and the group average, this participant was excluded from further analysis. 


\section{Imaging results}

Letter status effect. In the early retinotopic areas, ROI analysis revealed larger activation for letters than non-letters only in the horizontal presentation condition and only in the left V1/V2 area $(\mathrm{t}(17)=2.7, \mathrm{p}=$ .016). In this region, letters induced $8 \%$ more activation than nonletters (Fig. 6a).

The corresponding whole-brain SPM analysis revealed an interaction between letter status and orientation, namely, larger activation for letters than non-letters when presented in the horizontal meridian than in the vertical meridian, at an occipital site corresponding to left V1/V2 (94\% of the whole volume of the cluster)(Fig. $6 \mathrm{~b}$ and Table 3).

In the higher visual cortex, the ROI analysis revealed larger activation for non-letters in all ROIs except the left FG1 and FG2 (Fig. 7a). This effect was found only for horizontal presented stimuli in left V5 $(\mathrm{t}(17)=-3.0, \mathrm{p}=.008)$, LO1 $(\mathrm{t}(17)=-2.8, \mathrm{p}=.014)$, LO2 $(\mathrm{t}(17)=-3.3, \mathrm{p}=.004)$, VWFA $(\mathrm{t}(17)=-2.1 \mathrm{p}=.046)$, right V5 $(\mathrm{t}(17)=-2.5, \mathrm{p}=.023), \mathrm{LO} 1(\mathrm{t}(17)=-3.5, \mathrm{p}=.002), \mathrm{LO} 2$ $(\mathrm{t}(17)=-4.1, \mathrm{p}=.0007)$, FG1 $(\mathrm{t}(17)=-3.3, \mathrm{p}=.003)$, FG2 $(\mathrm{t}(17)=-2.9, \mathrm{p}=.011)$, and rVWFA $(\mathrm{t}(17)=-2.6, \mathrm{p}=.018)$. Larger activation for letters than non-letters was found only in right V5 $(t(17)=2.1, p=.047)$ for vertically presented stimuli.

A significant Interaction between orientation and letter status was found in the left V5 $(\mathrm{t}(547)=-2.5, \mathrm{p}=.01)$,VWFA $(\mathrm{t}(547)=-2.2$, $\mathrm{p}=.03)$, right $\mathrm{V} 5(\mathrm{t}(547)=-2.7, \mathrm{p}=.007), \mathrm{LO} 2(\mathrm{t}(547)=-2.6$, $\mathrm{p}=.009)$, FG1 $(\mathrm{t}(547)=-3.0, \mathrm{p}=.003)$, FG2 $(\mathrm{t}(547)=-2.6, \mathrm{p}=$ $.01)$, and rVWFA $(\mathrm{t}(547)=-3.0, \mathrm{p}=.005)$.

Consistent with the ROI analyses, results of whole-brain SPM analyses also revealed larger activation for non-letters than letters (Table 3, non-letters vs. letters) and an interaction between letter status and

A

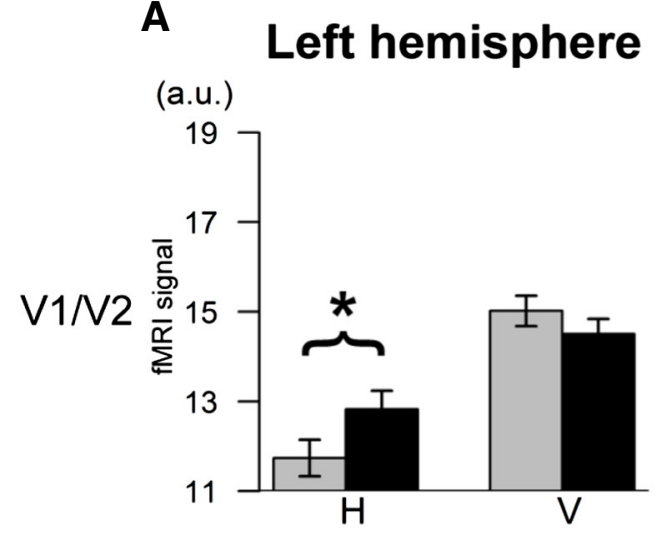

Right hemisphere
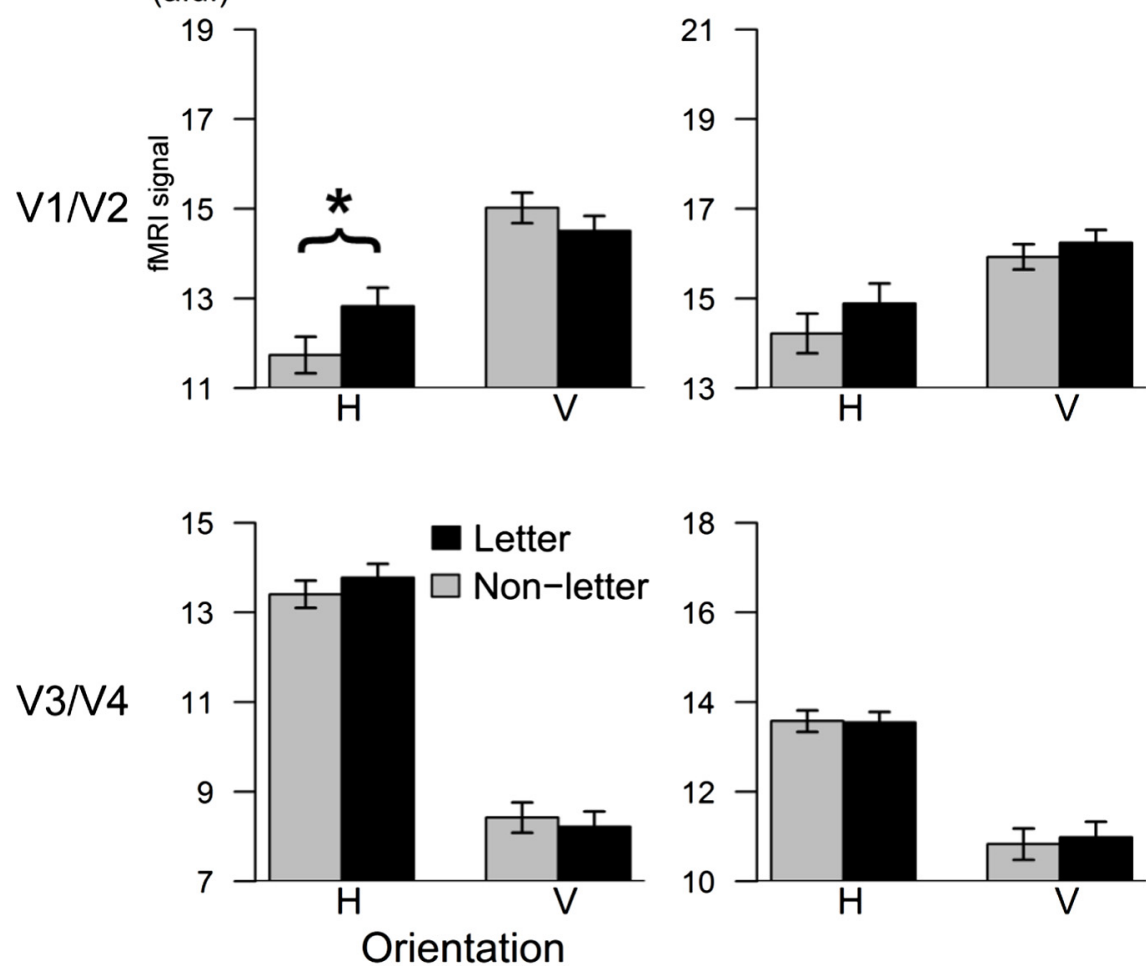

B

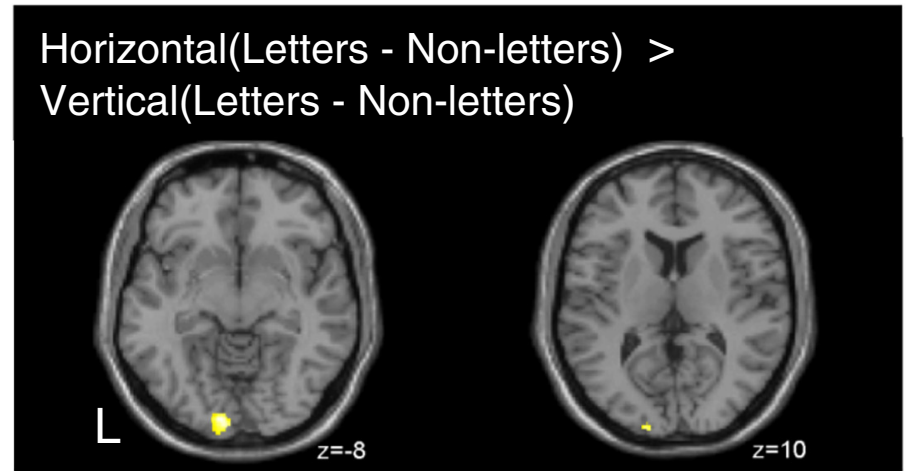

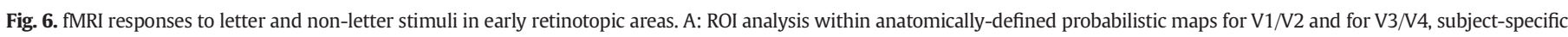

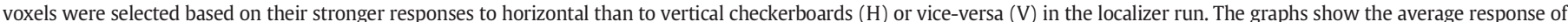

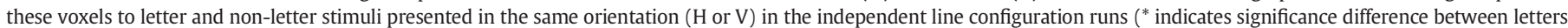

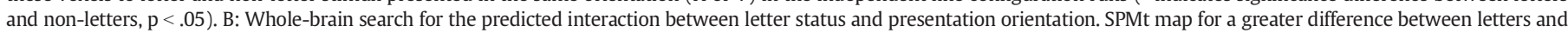
non-letters for horizontal than for vertical stimuli $(\mathrm{N}=18$, thresholded at $\mathrm{T}>3.12$, voxelwise $\mathrm{p}<.005$, uncorrected; clusterwise $\mathrm{p}<0.05$, FDR corrected). 
Table 3

Brain regions showing significant effects of letter status, orientation, natural-scene frequency, letter frequency, or the interactions between them in Experiment 2.

\begin{tabular}{|c|c|c|c|c|c|c|c|}
\hline Cluster Size & & & & $\mathrm{T}$ & $\mathrm{X}$ & $\mathrm{Y}$ & Z \\
\hline \multicolumn{8}{|c|}{ horizontal(letters vs. non-letters) > vertical(letters vs. non-letters) } \\
\hline \multirow[t]{3}{*}{543} & Occipital & Calcrine & $\mathrm{L}$ & 4.10 & -9 & -93 & -8 \\
\hline & & Lingual & $\mathrm{L}$ & 3.54 & -9 & -90 & -16 \\
\hline & & Mid. & $\mathrm{L}$ & 3.48 & -15 & -99 & 10 \\
\hline \multicolumn{8}{|c|}{ non-letters vs. letters } \\
\hline \multirow[t]{2}{*}{952} & Occipital & Mid. & $\mathrm{L}$ & 4.29 & -33 & -85 & 3 \\
\hline & & Inf. & $\mathrm{L}$ & 3.55 & -47 & -81 & -8 \\
\hline \multicolumn{8}{|c|}{ horizontal(non-letters vs. letters) > vertical(non-letters vs. letters) } \\
\hline \multirow[t]{3}{*}{577} & Occipital & Mid. & $\mathrm{R}$ & 3.96 & 42 & -82 & 1 \\
\hline & & Inf. & $\mathrm{R}$ & 3.27 & 35 & -82 & -5 \\
\hline & Temporal & Mid. & $\mathrm{R}$ & 3.48 & 51 & -69 & -2 \\
\hline \multicolumn{8}{|c|}{ horizontal(letter frequency) > vertical (letter frequency) } \\
\hline \multirow[t]{2}{*}{419} & Occipital & Cuneus & $\mathrm{R}$ & 3.74 & 21 & -96 & 10 \\
\hline & & Sup. & $\mathrm{R}$ & 3.51 & 26 & -93 & 19 \\
\hline \multicolumn{8}{|c|}{ orientation $\times$ letter status $\times$ letter frequency } \\
\hline \multirow[t]{3}{*}{1351} & Occipital & Inf. & $\mathrm{L}$ & 4.81 & -21 & -100 & -7 \\
\hline & & Mid. & $\mathrm{L}$ & 4.36 & -42 & -90 & -5 \\
\hline & & Inf. & $\mathrm{L}$ & 4.28313 & -35 & -93 & -11 \\
\hline \multirow[t]{3}{*}{825} & Occipital & Mid. & $\mathrm{R}$ & 4.26 & 33 & -91 & 4 \\
\hline & & Mid. & $\mathrm{R}$ & 4.13 & 38 & -88 & 12 \\
\hline & & Inf. & $\mathrm{R}$ & 3.83193 & 39 & -91 & -5 \\
\hline \multicolumn{8}{|c|}{ number of junctions } \\
\hline \multirow[t]{2}{*}{1346} & Occipital & Fusiform & $\mathrm{L}$ & 6.88 & -39 & -77 & -16 \\
\hline & & Inf. & $\mathrm{L}$ & 4.90 & -39 & -87 & -13 \\
\hline \multirow[t]{3}{*}{885} & & Inf. & $\mathrm{R}$ & 5.65 & 38 & -79 & -17 \\
\hline & & Inf. & $\mathrm{R}$ & 4.15 & 44 & -75 & -10 \\
\hline & & Fusiform & $\mathrm{R}$ & 3.68 & 36 & -69 & -14 \\
\hline
\end{tabular}

orientation in higher visual cortex (Table 3, horizontal(non-letters vs. letters) > vertical(non-letters vs. letters)). This interaction again showed that the increased activations to non-letters than letters were mainly found with the horizontal stimuli.

Natural-scene frequency and letter frequency effects. The fact that we failed to observed increasing brain activation for configurations with increasingly higher natural-scene frequency, either in SPM analyses or in ROI analyses, could result from the fact that after learning to read, the visual system is more sensitive to the frequencies of line configurations in texts rather than in the natural environment. To further test this idea, we examined the effect of the logarithm of letter frequency. Letter frequency was extracted from French texts, the subject's native language, and was weighted by the frequencies of the carrier words, regardless of case, as provided by www.LEXIQUE.org (New et al., 2001). Note that the correlation coefficient between natural-scene frequency and French letter frequency was positive but non-significant $(r=0.52, p=.26)$.

When we included letter status, orientation, natural-scene frequency, and letter frequency in the model for the ROI analysis, a three-way interaction among letter status, orientation, and letter frequency was observed in higher visual cortical areas including left LO1 $(\mathrm{t}(547)=$ $2.1, \mathrm{p}=.03), \mathrm{LO} 2(\mathrm{t}(547)=2.4, \mathrm{p}=.02)$, FG2 $(\mathrm{t}(547)=2.3, \mathrm{p}=$ $.02)$, VWFA $(\mathrm{t}(547)=2.6, \mathrm{p}=.008)$, right LO1 $(\mathrm{t}(547)=2.7, \mathrm{p}=$ $.008)$, LO2 $(\mathrm{t}(547)=2.6, \mathrm{p}=.01), \mathrm{FG} 2(\mathrm{t}(547)=2.7, \mathrm{p}=.007)$, and rVWFA $(\mathrm{t}(547)=2.7, \mathrm{p}=.006)$. The profile of this triple-interaction was consistent with an increase in activation with letter frequency, but only for letters and only in the horizontal position (see Fig. 7b). It also showed that non-letters only had larger activations compared to letters with low letter frequencies, but did not differ from high-letterfrequency ones. There was no effect in early retinotopic areas.

We further examined the letter frequency effect separately for horizontally presented letters, horizontally presented non-letters, vertically presented letters, and vertically presented non-letters. Significant letter frequency effects were only found in horizontal meridian. For letters, configurations with higher letter frequency elicited larger activation, while non-letters showed the opposite pattern. The regions showing a positive correlation between letter frequency and brain activation for horizontally presented letters were left LO2 $(\mathrm{t}(125)=3.04, \mathrm{p}=.003)$, left FG1 $(\mathrm{t}(125)=3.04, \mathrm{p}=.003$, left FG2 $(\mathrm{t}(125)=3.13, \mathrm{p}=.002)$, VWFA $(\mathrm{t}(125)=3.50, \mathrm{p}=.0006)$, right V5 $(\mathrm{t}(125)=3.18, \mathrm{p}=.002$, right LO1 $(\mathrm{t}(125)=3.50, \mathrm{p}=.0006)$, right LO2 $(\mathrm{t}(125)=2.87, \mathrm{p}=$ $.005)$, right FG1 $(\mathrm{t}(125)=2.44, \mathrm{p}=.02$, right FG2 $(\mathrm{t}(125)=3.47, \mathrm{p}=$ $.0007)$, and rVWFA ( $\mathrm{t}(125)=3.80, \mathrm{p}=.0002)$. The regions showing negative correlation between letter frequency and brain activation for horizontally presented non-letters were left LO1 $(\mathrm{t}(125)=-2.45, \mathrm{p}=$ $.02)$, right LO1 $(\mathrm{t}(125)=-2.36, \mathrm{p}=.02)$, right LO2 $(\mathrm{t}(125)=-2.37$, $\mathrm{p}=.02), \operatorname{rVWFA}(\mathrm{t}(125)=-2.00, \mathrm{p}=.05)$.

Consistent with the ROI analyses, voxel-based SPM analyses also showed an interaction between letter frequency and orientation, as well as a three-way interaction among letter frequency, letter status, and presentation orientation (Table 3).

Negative effect of natural-scene frequency and the role of junction number. As reported above, we did not observe any positive correlations between brain activations and natural-scene frequency. Although a negative correlation was found in the voxel-based analysis in bilateral ventral occipitotemporal cortex and in the ROI analysis in right LO2 $(\mathrm{t}(547)=-2.3, \mathrm{p}=$ $.02 ; \mathrm{t}(547)=2.3, \mathrm{p}=.03$ ), given the small number of items used, it could be due to confounded factors. One such confound could be the number of line junctions: the correlation coefficient between natural-scene frequency and number of junctions was -.62 ( $\mathrm{p}=0.10)$ (Appendix Table 2). Indeed, increased activation for configurations with more junctions was observed in the same regions, at a site plausibly corresponding with area V4 (V4 covered $61 \%$ and $30 \%$ of the volume of the cluster in right and left hemisphere respectively) (Fig. 8 and Table 3), and in a model where both variables were included, the negative correlation between natural-scene frequency and brain activation was no longer significant, while the number of junctions effect remained. We therefore went back to Experiment 1 and tested the number of junction effect. The same regions showing an effect of the number of junctions in Experiment 2 were also detected in Experiment 1 at a lower uncorrected threshold ( $p<.005$ voxelwise, uncorrected) (Fig. 8). We therefore conclude that the number of junctions drove this effect. Indeed, the finding of a bilateral ventral occipito-temporal effect of the presence of line junctions is congruent with prior findings by Szwed et al. (2011).

\section{Discussion}

In Experiment 1, we tested the hypothesis that the natural-scene frequency distribution of configurations is reflected in the human visual system. We found a positive effect, with bilateral occipital activations increasing with the frequencies of line configurations, but we also found that this effect was most likely due to the fact that many frequent configurations also depicted letters of the alphabet, and that the frequency effect disappeared once letter status was controlled for. In Experiment 2, we manipulated independently the effects of natural-scene frequency and letter status. As in Experiment 1, in early retinotopic areas, letters elicited more activation than non-letters. This effect was reversed in the higher visual cortex. Furthermore, no positive naturalscene frequency effect was found. Instead, a letter frequency effect was observed in the higher visual cortex. For letters, letter frequency was positively correlated with brain activations, while for non-letters, a tendency for a negative correlation between letter frequency and brain activations was found. Experiment 2 also included a novel factor, the orientation of presentation of the stimuli, which were arrayed along either the horizontal or the vertical meridian. We predicted that letter status effect would be stronger in brain regions corresponding to the horizontal meridian, which is the location where letter strings are usually presented during reading Indeed, both the letter status effect and the interaction between letter status and letter frequency were mainly found in regions corresponding to the horizontal meridian. 


\section{Left hemisphere Right hemisphere}
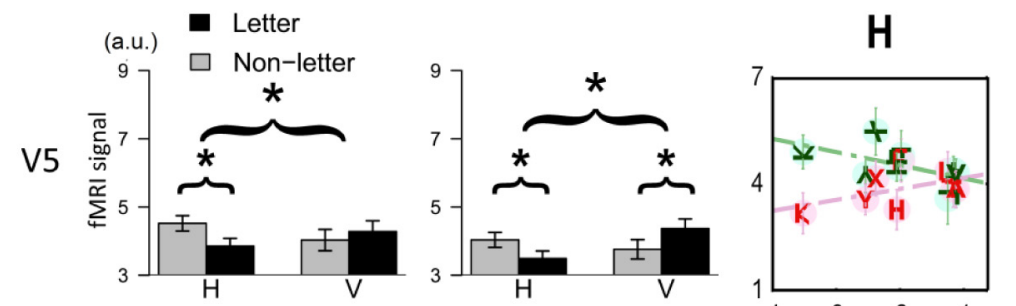

Left hemisphere

Right hemisphere
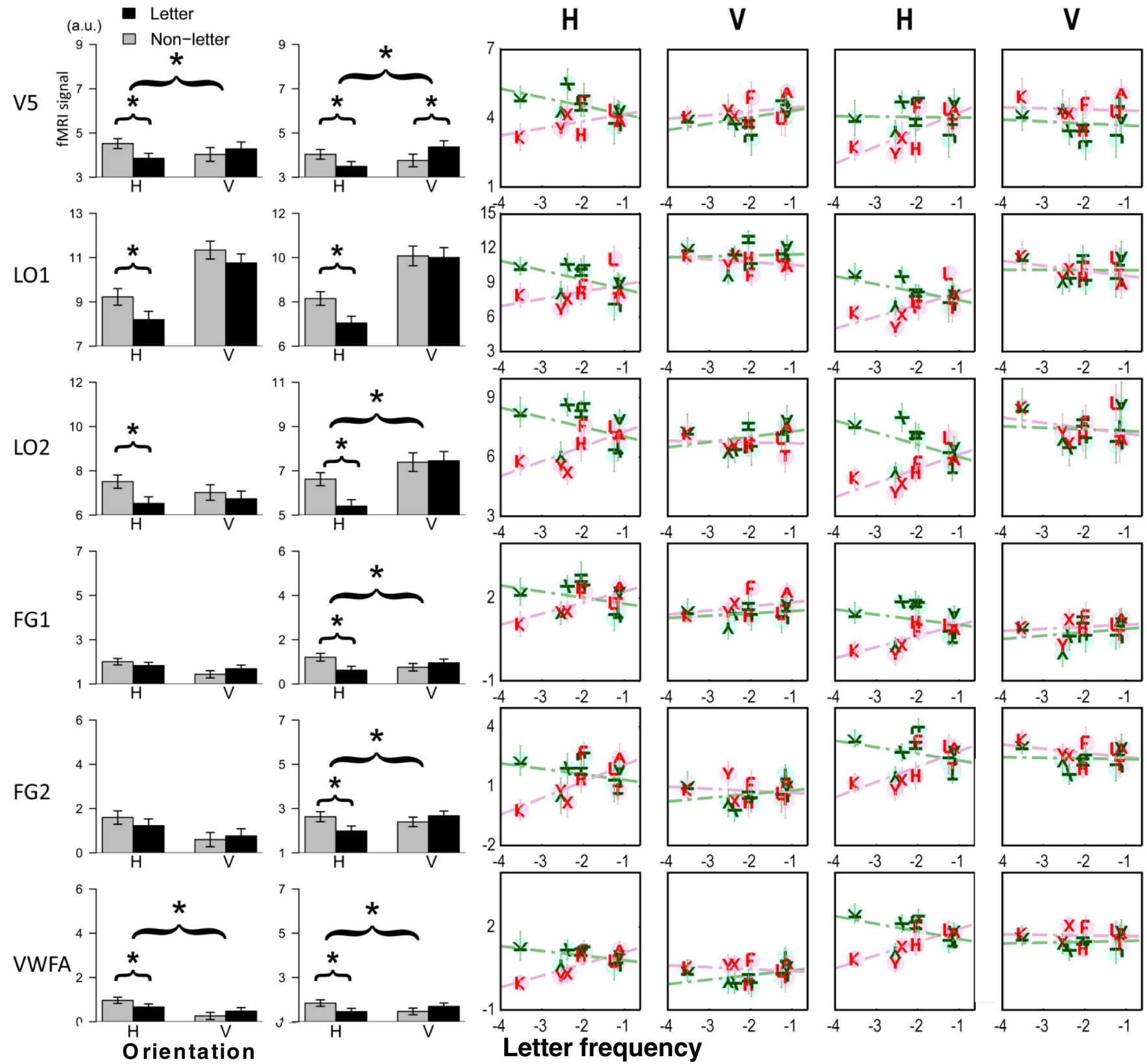

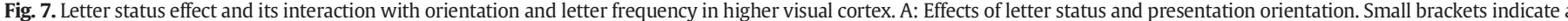

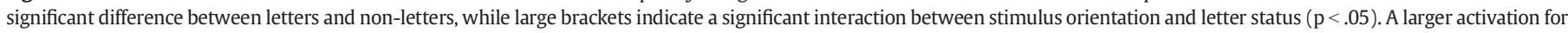

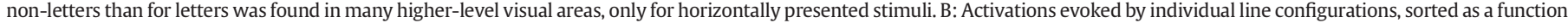
of letter frequency in the written language of the subjects. Again, an influence of letter frequency was only observed for horizontally presented stimuli.

Finally, aside from those effects of interest, an increased activation for configurations with more junctions was observed mainly in bilateral V4.

Line junctions are thought to be useful visual features of medium size and complexity along the hierarchy from simple line segments to entire objects or words. In this respect, our finding that line junctions cause an increased activation in area V4 is consistent with hierarchical models of visual recognition (Dehaene et al., 2005; DiCarlo et al., 2012; Rolls and Stringer, 2006; Serre et al., 2007; Ullman, 2007), which assume that a hierarchy of feature detectors of increasing complexity underlies the ventral occipito-temporal "what" pathway. A similar region was previously reported to respond more strongly to line drawings where the line junctions were preserved than when they were deleted (Szwed et al., 2011) (peak around $y=-70$ ). Behavioral studies also demonstrate that the presence of diagnostic line junctions facilitates the visual identification of objects and words (Beiderman and Cooper, 1991; Biederman, 1987; Szwed et al., 2011).

Our finding of larger activation to letters than to non-letters in early retinotopic areas, however, suggests that physical properties such as feature complexity and size are not the only factor determining the cortical representation of visual features. Rather, the history of perceptual experience, including literacy, must also be considered. This conclusion fits with studies of perceptual learning, showing that extensive training 


\section{Number of junctions effect}

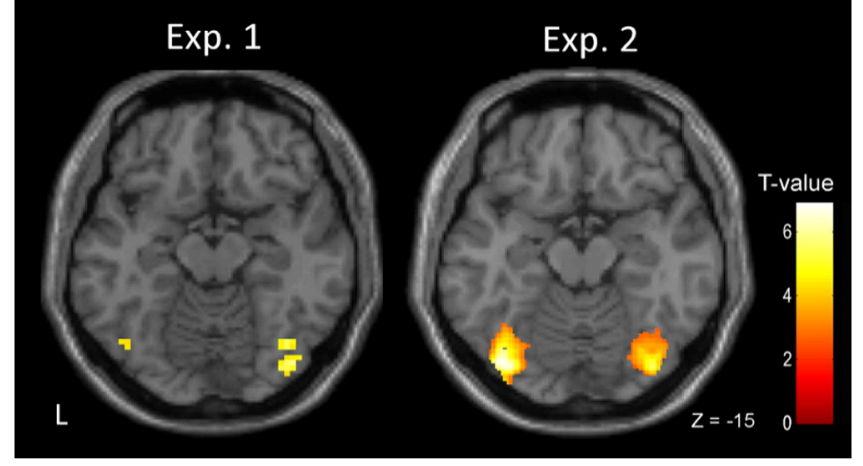

Fig. 8. Effect of the number of line junctions in Experiments 1 (left) and 2 (right). A regression model with letter status and number of junctions was used for Experiment 1 ( $\mathrm{N}=18$, thresholded at $\mathrm{p}<.005$, voxelwise $\mathrm{p}<.005$, uncorrected), while a contrast in the ANOVA model was used in Experiment $2(\mathrm{~N}=18$, thresholded at $\mathrm{T}>3.12$, voxelwise $\mathrm{p}<.005$, uncorrected; clusterwise $\mathrm{p}<0.05$, FDR corrected).

to detect a T shape yields increased activation in V1/V2 when this shape is presented in the trained orientation compared to untrained orientations (Sigman et al., 2005). In the reading domain, a similar early visual effect was observed when contrasting words versus scrambled words, particularly at an occipital cortical site corresponding to the horizontal meridian in the left hemisphere (Szwed et al., 2011, 2013). Further, this effect was absent for participants who were not native speakers of the tested language (Szwed et al., 2013). These findings, together with ours, support the hypothesis of an orientation- and location- specific adaptation in the early retinotopic areas, which is experience dependent and probably driven by the need for fast and parallel processing (Gilbert et al., 2001b; Gilbert and Sigman, 2007).

It is worth noting that letter selectivity has been previously observed in higher region of the ventral visual pathway, in tasks that required an interaction between the perceptual system and higher-order regions within the reading network. Using a semantic judgment task, Thesen et al. (2012) compared brain responses to letters, non-letters (false font), and real words. They found larger brain responses to letter than non-letters in the lateral posterior fusiform gyrus. This increased neural activity was sustained for an extended duration and was concomitant with the activation of a broad lexico-semantic processing network. Thus, Thesen et al. (2012) suggest that the selectivity to letters in this area depends on top-down influences accompanying high level reading tasks. The recent finding that this area's response to letter depends not only on previous experience but also on current context again suggests a top-down influence (Grotheer \& Kovács, 2014). Conversely, the adoption of a low-level perceptual task may explain why our study, like previous fMRI studies, did not show letter selectivity in lateral posterior fusiform gyrus (Tagamets and Novick, 2000; Vinckier et al., 2007).

Interestingly, we found that the letter status effect reversed in higher visual areas, where there was more activation for non-letters than for letters. Similarly, contrasts between $T$ shapes at untrained orientation versus trained orientation (Sigman et al., 2005), pseudo-letters versus real letters (Vinckier et al., 2007), and rotated words versus words in a normal orientation (Cohen et al., 2008) all yielded an increased activation in higher ventral occipito-temporal cortex. Those effects might reflect an on-line top-down influence, such as additional attention to unfamiliar configurations (Vinckier et al., 2007) or, conversely, decreased activation to familiar configurations, due to the possibility of top-down predictions (Price and Devlin, 2011). Since such top-down influences are known to be context-dependent (Gilbert et al., 2001a; Price and Devlin, 2011), the horizontal presentation could have offered the most appropriate context for letters and increased this top-down influence, thus providing a tentative explanation for why such an effect was only found with the horizontal stimuli in Experiment 2.

We also found a letter frequency effect in higher visual cortex. Consistent with this observation, previous studies found a larger activation for frequent letters and their combinations than for infrequent ones, an effect which grew from posterior to anterior occipital regions (Binder et al., 2006; Vinckier et al., 2007). We also observed, more surprisingly, a negative correlation between letter frequency and brain activations for non-letters. Non-letters with low letter frequencies yielded larger activations and accounted for the reversed letter status effect in higher visual cortex. This might reflect the fact that high-frequency letters are more resistant to rotations, thus facilitating their recognition under rotated conditions. Such resistance to rotation could result from neural representations generalized over broader angles (Ahissar and Hochstein, 2004; Folta, 2003).

While the effects of letter status and letter frequencies were salient, across two experiments, the current study did not provide any evidence for a natural-scene frequency effect. We did find an effect of naturalscene frequency in early retinotopic areas in Experiment 1, but it seemed to be entirely imputable to the presence of letters amongst the most frequent stimuli, and vanished once this factor was controlled in Experiment 2. Why did reading experience have such a massive impact on the visual processing of line configurations, while experience with natural scenes seemed to have no impact? Since we scanned students, one explanation is that letters have become the most frequent line configuration stimuli in their cultural environment, overriding any (putative) prior effect of natural scenes. Another explanation, not incompatible with the first one, is the distinction between active and passive perceptual learning. Attention and task requirements have been shown to deeply influence perceptual learning (Crist et al., 2001; Li et al., 2004, 2008; McManus et al., 2011). In their absence, perceptual learning is very reduced and occurs only under restricted conditions, e.g. when the unattended stimuli are paired up with attended stimuli (Seitz and Watanabe, 2003) or rewards (Seitz and Watanabe, 2009). Thus, letters might have benefited from the active and intensive experience of reading acquisition, while natural scenes are only perceived passively for the most part. The difference and interaction between the neural mechanisms underlying active and passive perceptual learnings are still unclear (Sasaki, Nanez, and Watanabe, 2010; Seitz and Dinse, 2007). Future studies on this subject will help to shed further light on our findings.

It is worth noting that although extensive training plays an important role in shaping early visual areas (Gilbert et al., 2001a; Sigman et al., 2005), there is clearly a limit on early cortical plasticity. Perceptual learning effect in early visual cortex has so far been mostly observed for relatively simple stimuli such as collinear segments (Zhang and Kourtzi, 2010), T shapes (Sigman et al., 2005), moving dots (Watanabe et al., 2002), or gratings (Folta, 2003; Frenkel et al., 2006). Converging evidence indicates that stimuli as complex as whole words, even after extensive reading experience, continue to rely on higher visual areas such as the VWFA (Dehaene and Cohen, 2011; Glezer et al., 2009; Glezer and Riesenhuber, 2013). In the current study, in contrast to the letter status effect in the early retinotopic areas, a bilateral letter frequency effect was only found in higher visual cortex. This result is in accordance with the local combination detectors model (Dehaene et al., 2005) and empirical data showing that case- and location-invariance is only achieved in higher visual cortex (Dehaene et al., 2001, 2004). The complexity of the shapes that can be recognized by neurons in a given area is likely to be strongly constrained by the underlying neural circuitry. For example, it is proposed that the horizontal connections between pyramidal cells in V1 (Gilbert and Wiesel, 1989; Stettler et al., 2002) enable subsets of neurons to represent complex visual features by integrating information beyond the classical receptive field (Gilbert et al., 2001b; Li et al., 2006, 2008; McManus et al., 2011). As a consequence, perceptual learning in V1 is likely to be constrained by the spatial extent of these connections, which 
extends over about 4 degree of visual space (Stettler et al., 2002), large enough to detect a simple configuration such as a letter, but probably not an entire word.

In summary, our main finding, across two experiments, is that the early visual cortex is highly attuned to literacy, to such an extent that learned letters induce a stronger activation than matched line configurations, especially when presented at the usual horizontal location where letters usually appear in written texts. Those results reaffirm the importance of literacy acquisition in shaping the human visual system (Dehaene et al., 2010; Pegado and Nakamura, 2014; Szwed et al., 2012). Nevertheless, the present study suffers from several limitations. First, it would have been useful to obtain a complete subject-specific delineation of visual areas and retinotopic maps. We did use a withinsubject localizer in Experiment 2, but given the time available for scanning, we were only able to define ROIs corresponding to horizontal and vertical meridians in early visual areas. Replicating the present results and testing their alignment with full retinotopic maps is an important goal for future search. Second, this study is also limited by the fact that only educated adults were recruited. Because the impact of letters is so strong, fMRI studies of educated adults are not ideal to properly evaluate the original hypothesis proposed by Changizi et al. (2006), according to which the visual system should also be attuned to natural-scene statistics. Future work should endeavor to replicate the present design, searching for natural-scene frequency effects in illiterate subjects (Dehaene et al., 2010), in children prior to the acquisition of reading (Monzalvo et al., 2012), or in monkeys without specific symbol training (Brincat and Connor, 2004; Hung et al., 2012; Yau et al., 2012).

\section{Acknowledgments}

We would like to thank the LBIOM team of the NeuroSpin center for their help in subject recruitment and scanning. We gratefully acknowledge Alexis Amadon, from NeuroSpin, for his help with high-resolution fMRI scanning, and Kamil Ugurbil, Essa Yacoub, Steen Moeller, Eddie Auerbach and Gordon Junqian Xu, from the Center for Magnetic Resonance Research, University of Minnesota, for sharing their pulse sequence and reconstruction algorithms. This research was funded by INSERM, CEA, Collège de France, University Paris XI, Agence Nationale de Recherche, and by TAIWAN GRANT NSC 99-2911-I-008507, NSC 100-2911-I-008-505, NSC 102-2410-H-010-004-MY2, and NSC 102-2911-I-010-507.

\section{Appendix A}

Appendix Table 1

Parameters for each configuration type in Experiment 1.

\begin{tabular}{|c|c|c|c|c|c|c|c|c|c|c|c|}
\hline Configuration & $\begin{array}{l}\text { Log natural-scene } \\
\text { frequency }\end{array}$ & $\begin{array}{l}\text { Log letter } \\
\text { frequency }\end{array}$ & $\begin{array}{l}\text { Number of } \\
\text { junctions }\end{array}$ & $\begin{array}{l}\text { Number of } \\
\text { terminals }\end{array}$ & $\begin{array}{l}\text { Number of } \\
\text { closures }\end{array}$ & $\begin{array}{l}\text { Number of } \\
\text { angles }\end{array}$ & $\begin{array}{l}\text { Number of } \\
\text { strokes }\end{array}$ & $\begin{array}{l}\text { Letter } \\
\text { status }\end{array}$ & $\begin{array}{l}\text { Convex area } \\
\text { (pixel) }\end{array}$ & RT & Accuracy \\
\hline$x$ & -1.44 & -2.38 & 1 & 4 & 0 & 4 & 2 & 1 & 448 & 446 & $96 \%$ \\
\hline$T$ & -0.67 & -1.16 & 1 & 3 & 0 & 2 & 2 & 1 & 475 & 460 & $94 \%$ \\
\hline$L$ & -0.66 & -1.25 & 1 & 2 & 0 & 1 & 2 & 1 & 505 & 463 & $97 \%$ \\
\hline$\Delta$ & -4.30 & & 3 & 2 & 1 & 5 & 3 & 0 & 256 & 446 & $99 \%$ \\
\hline$\underline{x}$ & -4.30 & & 3 & 2 & 1 & 6 & 3 & 0 & 230 & 429 & $98 \%$ \\
\hline $\bar{\Delta}$ & -3.07 & & 3 & 1 & 1 & 4 & 3 & 0 & 228 & 452 & $94 \%$ \\
\hline $\bar{A}$ & -2.71 & & 3 & 2 & 1 & 5 & 3 & 0 & 270 & 449 & $99 \%$ \\
\hline$\psi$ & -2.30 & & 1 & 4 & 0 & 4 & 3 & 0 & 357 & 453 & $96 \%$ \\
\hline 干 & -1.77 & & 2 & 5 & 0 & 6 & 3 & 0 & 323 & 440 & $99 \%$ \\
\hline F & -1.62 & & 2 & 4 & 0 & 4 & 3 & 0 & 398 & 442 & $99 \%$ \\
\hline$\neq$ & -1.59 & & 2 & 6 & 0 & 8 & 3 & 0 & 312 & 434 & $99 \%$ \\
\hline$Y$ & -1.51 & -2.54 & 1 & 3 & 0 & 3 & 3 & 1 & 523 & 447 & $95 \%$ \\
\hline$I$ & -1.47 & -2.05 & 2 & 4 & 0 & 4 & 3 & 1 & 451 & 439 & $98 \%$ \\
\hline $\bar{F}$ & -1.16 & -1.98 & 2 & 3 & 0 & 3 & 3 & 1 & 379 & 438 & $98 \%$ \\
\hline$\Rightarrow$ & -0.94 & & 2 & 4 & 0 & 4 & 3 & 0 & 345 & 442 & $97 \%$ \\
\hline
\end{tabular}

Appendix Table 2

Parameters for each configuration type in Experiment 2.

\begin{tabular}{|c|c|c|c|c|c|c|c|c|}
\hline Configuration & $\begin{array}{l}\text { Log natural-scene } \\
\text { frequency }\end{array}$ & $\begin{array}{l}\text { Log letter } \\
\text { frequency }\end{array}$ & $\begin{array}{l}\text { Number of } \\
\text { junctions }\end{array}$ & $\begin{array}{l}\text { Number of } \\
\text { terminals }\end{array}$ & $\begin{array}{l}\text { Number of } \\
\text { closures }\end{array}$ & $\begin{array}{l}\text { Number of } \\
\text { angles }\end{array}$ & $\begin{array}{l}\text { Number of } \\
\text { strokes }\end{array}$ & $\begin{array}{l}\text { Convex area } \\
\text { (pixel) }\end{array}$ \\
\hline A & -1.12 & -2.71 & 3 & 2 & 1 & 5 & 3 & 361 \\
\hline $\mathrm{F}$ & -1.98 & -1.16 & 2 & 3 & 0 & 2 & 3 & 388 \\
\hline $\mathrm{H}$ & -2.05 & -1.47 & 2 & 4 & 0 & 4 & 3 & 338 \\
\hline $\mathrm{K}$ & -3.52 & -2.03 & 1 & 4 & 0 & 3 & 3 & 347 \\
\hline $\mathrm{L}$ & -1.25 & -0.66 & 1 & 2 & 0 & 1 & 2 & 520 \\
\hline $\mathrm{T}$ & -1.16 & -0.67 & 1 & 3 & 0 & 2 & 2 & 503 \\
\hline $\mathrm{X}$ & -2.38 & -1.44 & 1 & 4 & 0 & 4 & 2 & 398 \\
\hline $\mathrm{Y}$ & -2.54 & -1.51 & 1 & 3 & 0 & 3 & 3 & 550 \\
\hline
\end{tabular}




\section{References}

Ahissar, M., Hochstein, S., 2004. The reverse hierarchy theory of visual perceptual learning. Trends Cogn. Sci. 8 (10), 457-464. http://dx.doi.org/10.1016/j.tics.2004.08.011.

Berkes, P., Orbán, G., Lengyel, M., Fiser, J., 2011. Spontaneous cortical activity reveals hallmarks of an optimal internal model of the environment. Science (New York, N.Y.) 33 (6013), 83-87. http://dx.doi.org/10.1126/science.1195870.

Biederman, I., 1987. Recognition-by-components: a theory of human image understanding. Psychol. Rev. 94 (2), 115-147 (Retrieved from http://www.ncbi.nlm.nih.gov/ pubmed/3575582).

Beiderman, I., Cooper, E., 1991. Priming contour deleted images. Cogn. Psychol. 23, 393-419 Retrieved from http://scholar.google.com/scholar?hl=en\&btnG= Search\&q=intitle:Priming + contour-deleted + images\#8.

Binder, J.J.R., Medler, D. a, Westbury, C.F., Liebenthal, E., Buchanan, L., 2006. Tuning of the human left fusiform gyrus to sublexical orthographic structure. NeuroImage 33 (2), 739-748 (Retrieved from http://www.sciencedirect.com/science/article/pii/ S1053811906007075)

Blakemore, C., Cooper, G., 1970. Development of the brain depends on the visual environment. Nature 228 (5270), 477-478. http://dx.doi.org/10.1038/228477a0.

Brett, M., Anton, J.-L., Valabrègue, R., Poline, J.-B., 2002. Region of interest analysis using an SPM toolbox. 8th International Conference on Functional Mapping of the Human Brain. Sendai, Japan.

Brincat, S.L., Connor, C.E., 2004. Underlying principles of visual shape selectivity in posterior inferotemporal cortex Nat Neurosci. 7 (8), 880-886. http://dx.doi.org/10.1038/nn1278.

Brincat, S.L., Connor, C.E., 2006. Dynamic shape synthesis in posterior inferotemporal cortex. Neuron 49 (1), 17-24. http://dx.doi.org/10.1016/j.neuron.2005.11.026.

Brunswik, E., 1956. Perception and the representative design of psychological experiments, vol. 6 (Retrieved from http://www.google.com.tw/books?hl=zh-TW\&lr= \&id=xTwwQvk6XCUC\&pgis $=1$ )

Caspers, J., Zilles, K., Eickhoff, S.B., Schleicher, A., Mohlberg, H., Amunts, K., 2013. Cytoarchitectonical analysis and probabilistic mapping of two extrastriate areas of the human posterior fusiform gyrus. Brain Struct. Funct. 218 (2), 511-526. http://dx.doi.org/10.1007/s00429-012-0411-8.

Changizi, M.A., Zhang, Q., Ye, H., Shimojo, S., 2006. The structures of letters and symbols throughout human history are selected to match those found in objects in natura scenes The, S., Naturalist, A., \& May, N. Am. Nat. 167 (5), E117-E139. http://dx.doi. org/10.1086/502806.

Cohen, L., Lehéricy, S., Chochon, F., Lemer, C., 2002. Language-specific tuning of visual cortex? Functional properties of the Visual Word Form Area. Brain 125, 1054-1069 Retrieved from http://brain.oxfordjournals.org/content/125/5/1054.short

Cohen, L., Dehaene, S., Vinckier, F., Jobert, A., Montavont, A., 2008. Reading normal and degraded words: contribution of the dorsal and ventral visual pathways. NeuroImage 40 (1), 353-366. http://dx.doi.org/10.1016/j.neuroimage.2007.11.036.

Crist, R., Li, W., Gilbert, C., 2001. Learning to see: experience and attention in primary visual cortex. Nat. Neurosci. 4, 519-525 Retrieved from http://www.nature.com/neuro/ journal/v4/n5/abs/nn0501_519.html.

Dehaene, S., 2009. Reading in the brain: The new science of how we read. (Retrieved from http://books.google.com/books?hl=zh-TW\&lr=\&id=NIYsTqta7SYC\&pgis=1)

Dehaene, S., Cohen, L., 2011. The unique role of the visual word form area in reading. Trends Cogn. Sci. 15 (6), 254-262. http://dx.doi.org/10.1016/j.tics.2011.04.003.

Dehaene, S., Naccache, L., Cohen, L., Bihan, D.L., Mangin, J.F., Poline, J.B., Rivière, D., 2001 Cerebral mechanisms of word masking and unconscious repetition priming. Nat Neurosci. 4 (7), 752-758. http://dx.doi.org/10.1038/89551.

Dehaene, S., Jobert, A., Naccache, L., Ciuciu, P., Poline, J.B., Le Bihan, D., Cohen, L., 2004 Letter binding and invariant recognition of masked words: behavioral and neuroimaging evidence. Psychol. Sci. 15 (5), 307-313. http://dx.doi.org/10.1111/j.0956-7976. 2004.00674.x

Dehaene, S., Cohen, L., Sigman, M., Vinckier, F., 2005. The neural code for written words: a proposal. Trends Cogn. Sci. 9 (7), 335-341. http://dx doi.org/10.1016/j.tics.2005.05.004.

Dehaene, S., Pegado, F., Braga, L.W., Ventura, P., Nunes Filho, G., Jobert, A., ..., Cohen, L, 2010. How learning to read changes the cortical networks for vision and language. Science 330 (6009), 1359-1364. http://dx.doi.org/10.1126/science.1194140.

DiCarlo, J.J., Zoccolan, D., Rust, N.C., 2012. How does the brain solve visual object recognition? Neuron 73 (3), 415-434. http://dx.doi.org/10.1016/j.neuron.2012.01.010.

Eickhoff, S., Stephan, K., Mohlberg, H., 2005. A new SPM toolbox for combining probabilistic cytoarchitectonic maps and functional imaging data. Neuroimage 25 (4), 1325-1335. http://dx.doi.org/10.1016/j.neuroimage.2004.12.034.

Engel, S., Glover, G., Wandell, B., 1997. Retinotopic organization in human visual cortex and the spatial precision of functional MRI. Cereb. Cortex 7 (2), 181-192 Retrieved from http://cercor.oxfordjournals.org/content/7/2/181.short

Feinberg, D., Moeller, S., Smith, S., 2010. Multiplexed echo planar imaging for sub-second whole brain FMRI and fast diffusion imaging. PloS one 5 (12), e15710 Retrieved from http://dx.plos.org/10.1371/journal.pone.0015710.

Folta, K., 2003. Neural fine tuning during Vernier acuity training? Vis. Res. 43 (10), 1177-1185. http://dx.doi.org/10.1016/S0042-6989(03)00041-5.

Frenkel, M.Y., Sawtell, N.B., Diogo, A.C.M., Yoon, B., Neve, R.L., Bear, M.F., 2006. Instructive effect of visual experience in mouse visual cortex. Neuron 51 (3), 339-349. http://dx doi.org/10.1016/j.neuron.2006.06.026.

Furmanski, C.S., Engel, S.A., 2000. An oblique effect in human primary visual cortex. Nat. Neurosci. 3 (6), 535-536. http://dx.doi.org/10.1038/75702.

Geisler, W.S., 2008. Visual perception and the statistical properties of natural scenes. Annu. Rev. Psychol. 59, 167-192. http://dx.doi.org/10.1146/annurev.psych.58.110405. 085632.

Gilbert, C.D., Sigman, M., 2007. Brain states: top-down influences in sensory processing. Neuron 54 (5), 677-696. http://dx.doi.org/10.1016/j.neuron.2007.05.019.
Gilbert, C.D., Wiesel, T.N., 1989. Columnar specificity of intrinsic horizontal and corticocortical connections in cat visual cortex. J. Neurosci. Off. J. Soc. Neurosci. 9 (7), 2432-2442 (Retrieved from http://www.ncbi.nlm.nih.gov/pubmed/2746337).

Gilbert, C.D., Sigman, M., Crist, R., 2001a. The neural basis of perceptual learning. Neuron 31 (5), 681-697 (Retrieved from http://www.sciencedirect.com/science/article/pii/ S089662730100424X)

Gilbert, C.D., Sigman, M., Crist, R.R.E., 2001b. The neural basis of perceptual learning. Neuron 31 (5), 681-697 (Retrieved from http://www.sciencedirect.com/science/article/ pii/S089662730100424X)

Girshick, A.R., Landy, M.S., Simoncelli, E.P., 2011. Cardinal rules: visual orientation perception reflects knowledge of environmental statistics. Nat. Neurosci. 14 (7), 926-932. http://dx.doi.org/10.1038/nn.2831.

Glezer, L.S., Riesenhuber, M., 2013. Individual variability in location impacts orthographic selectivity in the "visual word form area". J. Neurosci. Off. J. Soc. Neurosci. 33 (27), 11221-11226. http://dx.doi.org/10.1523/JNEUROSCI.5002-12.2013.

Glezer, L.S., Jiang, X., Riesenhuber, M., 2009. Evidence for highly selective neuronal tuning to whole words in the "visual word form area". Neuron 62 (2), 199-204. http://dx. doi.org/10.1016/j.neuron.2009.03.017.

Grotheer, M., Kovács, G., 2014. Repetition probability effects depend on prior experiences. J. Neurosci. 34 (19), 6640-6646. http://dx.doi.org/10.1523/JNEUROSCI.5326-13.2014.

Harvey, B.M., Dumoulin, S.O., 2011. The relationship between cortical magnification factor and population receptive field size in human visual cortex: constancies in cortical architecture. J. Neurosci. Off. J. Soc. Neurosci. 31 (38), 13604-13612. http://dx.doi.org/ 10.1523/JNEUROSCI.2572-11.2011.

Held, R., Hein, A., 1963. Movement-produced stimulation in the development of visually guided behavior. J. Comp. Physiol. Psychol. 56 (5), 872-876 Retrieved from http:// citeseerx.ist.psu.edu/viewdoc/summary?doi=10.1.1.211.8253.

Hess, R.F., Hayes, A., Field, D.J., 2003. Contour integration and cortical processing. J. Physiol. Paris 97 (2-3), 105-119. http://dx.doi.org/10.1016/j.jphysparis.2003.09. 013.

Howe, C.Q., Purves, D., 2002. Range image statistics can explain the anomalous perception of length. Proc. Natl. Acad. Sci. U. S. A. 99 (20), 13184-13188. http://dx.doi.org/10. 1073/pnas.162474299.

Hung, C.-C., Carlson, E.T., Connor, C.E., 2012. Medial axis shape coding in macaque inferotemporal cortex. Neuron 74 (6), 1099-1113. http://dx.doi.org/10.1016/j. neuron.2012.04.029.

Kersten, D., Mamassian, P., Yuille, A., 2004. Object perception as Bayesian inference. Annu. Rev. Psychol. 55, 271-304. http://dx.doi.org/10.1146/annurev.psych.55.090902. 142005.

Knill, D.C., Pouget, A., 2004. The Bayesian brain: the role of uncertainty in neural coding and computation. Trends Neurosci. 27 (12), 712-719. http://dx.doi.org/10.1016/j. tins.2004.10.007.

Larsson, J., Heeger, D.J., 2006. Two retinotopic visual areas in human lateral occipital cortex. J. Neurosci. 26 (51), 13128-13142. http://dx.doi.org/10.1523/jneurosci.1657-06.2006.

Li, W., Piëch, V., Gilbert, C.D., 2004. Perceptual learning and top-down influences in primary visual cortex. Nat. Neurosci. 7 (6), 651-657 (Retrieved from http://www.nature.com/ neuro/journal/v7/n6/abs/nn1255.html).

Li, W., Piëch, V., Gilbert, C.D., 2006. Contour saliency in primary visual cortex. Neuron 50 (6), 951-962. http://dx.doi.org/10.1016/j.neuron.2006.04.035.

Li, W., Piëch, V., Gilbert, C.D., 2008. Learning to link visual contours. Neuron 57 (3), 442-451. http://dx.doi.org/10.1016/j.neuron.2007.12.011

Long, F., Purves, D., 2003. Natural scene statistics as the universal basis of color context effects. Proc. Natl. Acad. Sci. U. S. A. 100 (25), 15190-15193. http://dx.doi.org/10. 1073/pnas.2036361100.

Maldjian, J.a., Laurienti, P.J., Kraft, R.a., Burdette, J.H., 2003. An automated method for neuroanatomic and cytoarchitectonic atlas-based interrogation of fMRI data sets. NeuroImage 19 (3), 1233-1239. http://dx.doi.org/10.1016/S1053-8119(03)00169-1.

McManus, J.N.J., Li, W., Gilbert, C.D., 2011. Adaptive shape processing in primary visual cortex. Proc. Natl. Acad. Sci. U. S. A. 108 (24), 9739-9746. http://dx.doi.org/10.1073/ pnas. 1105855108

Moeller, S., Yacoub, E., Olman, C.A., Auerbach, E., Strupp, J., Harel, N., Uğurbil, K., 2010. Multiband multislice GE-EPI at 7 tesla, with 16 -fold acceleration using partial parallel imaging with application to high spatial and temporal whole-brain fMRI. Magn. Reson. Med. 63 (5), 1144-1153. http://dx.doi.org/10.1002/mrm.22361.

Monzalvo, K., Fluss, J., Billard, C., Dehaene, S., Dehaene-Lambertz, G., 2012. Cortical networks for vision and language in dyslexic and normal children of variable socioeconomic status. NeuroImage 61 (1), 258-274. http://dx.doi.org/10.1016/j. neuroimage.2012.02.035.

Nazir, T. a, Ben-Boutayab, N., Decoppet, N., Deutsch, A., Frost, R., 2004. Reading habits, perceptual learning, and recognition of printed words. Brain Lang. 88 (3), 294-311. http://dx.doi.org/10.1016/S0093-934X(03)00168-8.

New, B., Pallier, C., Ferrand, L., Matos, R., 2001. Une base de données lexicales du français contemporain sur internet: LEXIQUE. Annee Psychol. 101 (3), 447-462 (Retrieved from http://dialnet.unirioja.es/servlet/articulo?codigo $=3228917 \&$ info $=$ resumen $\&$ idioma $=\mathrm{ENG}$ ).

Pegado, F., Nakamura, K., 2014. Literacy breaks mirror invariance for visual stimuli: a behavioral study with adult illiterates. J. Exp. Psychol. 143 (2), 887-894 Retrieved from http://psycnet.apa.org/journals/xge/143/2/887/.

Price, C.J., Devlin, J.T., 2011. The interactive account of ventral occipitotemporal contributions to reading. Trends Cogn. Sci. 15 (6), 246-253. http://dx.doi.org/10.1016/j.tics. 2011.04.001.

Rolls, E.T., Stringer, S.M., 2006. Invariant visual object recognition: a model, with lighting invariance. J. Physiol. Paris 100 (1-3), 43-62. http://dx.doi.org/10.1016/j.jphysparis. 2006.09.004

Sasaki, Y., Nanez, J.E., Watanabe, T., 2010. Advances in visual perceptual learning and plasticity. Nat. Rev. Neurosci. 11 (1), 53-60. http://dx.doi.org/10.1038/nrn2737. 
Seitz, A.R., Watanabe, T., 2003. Psychophysics: Is subliminal learning really passive? Nature 422 (6927), 36. http://dx.doi.org/10.1038/422036a.

Seitz, A.R., Dinse, H.R., 2007. A common framework for perceptual learning. Curr. Opin. Neurobiol. 17 (2), 148-153. http://dx.doi.org/10.1016/j.conb.2007.02.004.

Seitz, A.R., Watanabe, T., 2009. The phenomenon of task-irrelevant perceptual learning. Vis. Res. 49 (21), 2604-2610. http://dx.doi.org/10.1016/j.visres.2009.08.003.

Serre, T., Oliva, A., Poggio, T., 2007. A feedforward architecture accounts for rapid categorization. Proc. Natl. Acad. Sci. U. S. A. 104 (15), 6424-6429. http://dx.doi.org/10.1073/ pnas.0700622104.

Shepard, R.N., 2002. Perceptual-cognitive universals as reflections of the world. Behav. Brain Sci. 24 (04), 581-601. http://dx.doi.org/10.1017/S0140525X01000012.

Sigman, M., Pan, H., Yang, Y., Stern, E., Silbersweig, D., Gilbert, C.D., 2005. Top-down reorganization of activity in the visual pathway after learning a shape identification task. Neuron 46 (5), 823-835. http://dx.doi.org/10.1016/j.neuron.2005.05.014.

Simoncelli, E., Olshausen, B., 2001. Natural image statistics and neural representation. Annu. Rev. Neurosci. 24, 1193-1216 Retrieved from http://www.annualreviews. org/doi/pdf/10.1146/annurev.neuro.24.1.1193.

Stettler, D.D., Das, A., Bennett, J., Gilbert, C.D., 2002. Lateral connectivity and contextual interactions in macaque primary visual cortex. Neuron 36 (4), 739-750 (Retrieved from http://www.sciencedirect.com/science/article/pii/S0896627302010292).

Szwed, M., Dehaene, S., Kleinschmidt, A., Eger, E., Valabrègue, R., Amadon, A., Cohen, L., 2011. Specialization for written words over objects in the visual cortex. Neurolmage 56 (1), 330-344. http://dx.doi.org/10.1016/j.neuroimage.2011.01.073.

Szwed, M., Ventura, P., Querido, L., Cohen, L., Dehaene, S., 2012. Reading acquisition enhances an early visual process of contour integration. Dev. Sci. 15 (1), 139-149. http://dx.doi.org/10.1111/j.1467-7687.2011.01102.x.

Szwed, M., Qiao, E., Jobert, A., Dehaene, S., Cohen, L., 2013. Effects of literacy in early visual and occipitotemporal areas of Chinese and French readers. 1-33 (Retrieved from http://www.mitpressjournals.org/doi/abs/10.1162/jocn_a_00499).

Szwed, M., Qiao, E., Jobert, A., Dehaene, S., Cohen, L., 2014. Effects of literacy in early visual and occipitotemporal areas of Chinese and French readers. (Retrieved from http://www.mitpressjournals.org/doi/abs/10.1162/jocn_a_00499\#.VCgW8RaTBdQ).

Tagamets, M., Novick, J., 2000. A parametric approach to orthographic processing in the brain: an fMRI study. J. Cogn. Neurosci. 12 (2), 281-297 Retrieved from http:// www.ncbi.nlm.nih.gov/pubmed/10771412.
Tanaka, K., 2003. Columns for complex visual object features in the inferotemporal cortex: clustering of cells with similar but slightly different stimulus selectivities. Cereb. Cortex 13 (1), 90-99. http://dx.doi.org/10.1093/cercor/13.1.90.

Thesen, T., McDonald, C.R.C., Carlson, C., Doyle, W., Cash, S., Sherfey, J., Felsovalyi, O. Girard, H., Barr, W., Devinsky, O., Kuzniecky, R., Halgren, E., 2012. Sequential then interactive processing of letters and words in the left fusiform gyrus. Nat. Commun. 3, 1284. http://dx.doi.org/10.1038/ncomms2220.

Tzourio-Mazoyer, N., Landeau, B., Papathanassiou, D., Crivello, F., Etard, O, Delcroix, N. Mazoyer, B., Joliot, M., 2002. Automated Anatomical Labeling of Activations in SPM Using a Macroscopic Anatomical Parcellation of the MNI MRI Single-Subject Brain Neuroimage 15 (1), 273-289. http://dx.doi.org/10.1006/nimg.2001.0978.

Ullman, S., 2007. Object recognition and segmentation by a fragment-based hierarchy. Trends Cogn. Sci. 11 (2), 58-64. http://dx.doi.org/10.1016/j.tics.2006.11.009.

Vinckier, F., Dehaene, S., Jobert, A., Dubus, J.P., Sigman, M., Cohen, L., 2007. Hierarchical coding of letter strings in the ventral stream: dissecting the inner organization of the visual word-form system. Neuron 55 (1), 143-156. http://dx.doi.org/10.1016/j. neuron.2007.05.031.

Watanabe, T., Náñez, J.E., Koyama, S., Mukai, I., Liederman, J., Sasaki, Y., 2002. Greater plasticity in lower-level than higher-level visual motion processing in a passive perceptual learning task. Nat. Neurosci. 5 (10), 1003-1009. http://dx.doi.org/10.1038/nn915.

Wotawa, N., Thirion, B., Castet, E., Anton, J.-L., Faugeras, O., 2005. Human retinotopic mapping using fMRI. Technical Report 5472, INRIA Sophia-Antipolis.

Xu, J., Moeller, S., Auerbach, E., Strupp, J., 2013. Evaluation of slice accelerations using multiband echo planar imaging at 3T. Neuroimage 93, 991-1001 Retrieved from http:// www.sciencedirect.com/science/article/pii/S1053811913008240.

Yau, J., Pasupathy, A., Brincat, S., Connor, C., 2012. Curvature processing dynamics in macaque area V4. Cereb. Cortex 23 (1), 198-209. http://dx.doi.org/10.1093/cercor/ bhs004.

Zhang. J., Kourtzi, Z., 2010. Learning-dependent plasticity with and without training in the human brain. Proc. Natl. Acad. Sci. U. S. A. 107 (30), 13503-13508. http://dx.doi.org/ 10.1073/pnas.1002506107. 